\title{
Sertoli-immature spermatids disengagement during testis regression in the armadillo
}

\author{
Valeria Merico ${ }^{1,2, *}$, Juan Pablo Luaces ${ }^{3,4, *}$, Luis Francisco Rossi ${ }^{3,4}$, Paola Rebuzzini ${ }^{1}$, \\ Maria Susana Merani ${ }^{3,4}$, Maurizio Zuccotti ${ }^{1,2}$ and SilviaGaragna ${ }^{1,2}$ \\ ${ }^{1}$ Dipartimento di Biologia e Biotecnologie 'Lazzaro Spallanzani', Laboratorio di Biologia dello Sviluppo, Università \\ degli Studi di Pavia, Pavia, Italy, ${ }^{2}$ Centre for Health Technology, Università degli Studi di Pavia, Pavia, Italy, \\ ${ }^{3}$ Laboratorio de Biología Cromosómica, Facultad de Medicina, UBA, Buenos Aires, Argentina and ${ }^{4}$ Consejo \\ Nacional de Investigaciones Cientificas y Técnicas, Buenos Aires, Argentina \\ Correspondence should be addressed to M S Merani or M Zuccotti or S Garagna; Email: mmerani@fmed.uba.ar or maurizio. \\ zuccotti@unipv.it or silvia.garagna@unipv.it
}

*(V Merico and J P Luaces contributed equally to this work)

\begin{abstract}
In nature, mammalian seasonal breeders undergo spermatogenetic arrest during the non-breeding season. In the large hairy armadillo Chaetophractus villosus, testis regression initiates with immature post-meiotic germ cells sloughing into the tubule lumen and continues with the death of the remaining spermatocytes. At the end of the regression period, only spermatogonia and Sertoli cells persist in the seminiferous epithelium. It has been suggested that cell sloughing is determined by changes in the adhesion complexes between Sertoli cells and spermatids, which are mediated by low intra-testicular testosterone levels. By immunofluorescence and Western blotting we studied key proteins of the $\mathrm{N}$-cadherin/ $\mathrm{N}$-cadherin and A6B1-integrin/laminin interlocks that contribute to the complex Sertoli/spermatid adhesion system throughout the eight stages of the seminiferous epithelium cycle in the comparison between active and regressing testes. In active testis, B1-integrin, laminin G3, N-cadherin, B-catenin, P-B-catenin-Tyr ${ }^{654}$, FAK, P-FAK-Tyr ${ }^{397}$, SRC, P-SRC-Tyr ${ }^{416}$ proteins present a spermatogenetic cycle-dependent localisation pattern, unmaintained in regressing testes. In the latter, quantitative variations and changes in the phosphorylation state of protein FAK, SRC and B-catenin contribute to the disassembly of the $\mathrm{N}$-cadherin/ $\mathrm{N}$-cadherin and A6B1-integrin/laminin interlocks, thus promoting the massive release of immature spermatids.

Reproduction (2019) 157 27-42
\end{abstract}

\section{Introduction}

Seasonal reproduction in the non-equatorial regions of the planet is an adaptive strategy aimed at assuring newborns the best environment for survival. During the non-reproductive season, block of the ovarian function and reduction or interruption of the testis activity determines the inability to produce offspring (for a review Jimenez et al. 2015). Spermatogenetic arrest has been described in several mammalian species including the Iberian mole (Dadhich et al. 2010, 2013), the hamster (Bex \& Bartke 1977), the black bear (Tsubota et al. 1997), the white-footed mouse (Young et al. 1999) and the large hairy armadillo Chaetophractus villosus whose seminiferous epithelium undergoes, once a year, rapid regression (Luaces et al. 2013, 2014).

In C. villosus, two subsequent waves of germ cell loss lead to the sole presence of spermatogonia and Sertoli cells in fully regressed testes. During the first wave, live immature spermatids exfoliate and drop into the tubule lumen, where they initiate apoptosis. Then, in a second wave, residual germ cells complete apoptosis and are eliminated by the phagocytic activity of Sertoli cells (Luaces et al. 2014). Reduction in the extension of vimentin intermediate filaments and altered localisation of the integral membrane nectin-3, $\mathrm{N}$-cadherin and the adaptor $\beta$-catenin proteins suggest that the dissociation of adherens junctions (AJ) at the Sertoli-spermatids interface is involved in this massive shedding of immature post-meiotic germ cells (Luaces et al. 2014). Similarly, in the Iberian mole, altered localisation of the Sertoli germ cell adhesion proteins $\mathrm{B}$-catenin, $\mathrm{N}$-cadherin and E-cadherin was associated to germ cell desquamation leading to testis regression during the non-reproductive season (Dadhich et al. 2013).

In both the large hairy armadillo and the Iberian mole, the rapid decrease of intra-testicular and serum testosterone levels correlate with massive post-meiotic germ cell depletion (Dadhich et al. 2013, Luaces et al. 2014). In the rat, testosterone withdrawal experiments 
have shown a causal link between hormone levels and the detachment of immature spermatids from the seminiferous epithelium by compromising the apical ectoplasmic specialisation (ES) (O'Donnell et al. 2000, Zhang et al. 2005, for a review Lui \& Lee 2009). Apical ES are testis-specific anchoring junctions present at the Sertoli-spermatid (step 8 and beyond in the mouse, Russell \& Malone 1980) interface, formed by multiple types of cell junctions such as AJ (N-cadherin/B-catenin and nectins/afadin complexes), focal contacts (A6B1integrin/laminin 333 complexes) and tight junctions (e.g. Jam-C) (for a review Berruti \& Paiardi 2014). In the rat, when testosterone levels are experimentally reduced, integrins of the A6B1-integrin/laminin G3 complex dissociate from the focal adhesion kinase (FAK)/c-SRC complex present in the Sertoli cell cytoplasm, while B1-integrin protein levels increase together with Tyr phosphorylation of both FAK and of SRC (P-FAK and P-SRC; for a review Wong et al. 2008). The increment of the P-FAK/SRC complex levels likely activates the extracellular signal-regulated kinase pathway, which favours the activity of the matrix metalloprotease 2 (MMP2). In testosterone-suppressed testis, dissociation of the $\mathrm{N}$-cadherin/ $\mathrm{N}$-cadherin interlocks also correlates to germ cell loss (Zhang et al. 2005). Compromised integrity of the cadherin/cadherin interlocks is mediated by phosphorylation of B-catenin at $\mathrm{Tyr}^{654}$ (P-B-catenin) (Zhang et al. 2005), the latter a peripheral adaptor protein of the actin-linked $\mathrm{N}$-cadherin/B-catenin complexes. Increase in Tyr phosphorylation of B-catenin determines the loss of protein-protein interactions between $\mathrm{N}$-cadherins and $\mathrm{B}$-catenins and between B-catenin and SRC (which binds the cadherin/catenin complex via catenin, Lee \& Cheng 2005) contributing to AJ disruption (Zhang et al. 2005).

Overall, these studies on testosterone-depletion model animals indicate that the quantity and phosphorylation state of key proteins of the cell-anchoring junctions are critical for the stability of the apical ES, whose loss of integrity leads to the release of immature spermatids. This knowledge is lacking for the large hairy armadillo, a seasonal reproducer in which, during the circannual cycle of its testis functional arrest, a seminiferous epithelium regression occurs under a 12 -fold decrease of the intra-testicular-testosterone level (Luaces et al. 2013).

Our study was aimed at understanding whether the disengagement of immature post-meiotic cells occurring at the beginning of the seminiferous epithelium regression associates with quali/quantitative and localisation changes of key proteins of the $\mathrm{N}$-cadherin/ $\mathrm{N}$-cadherin and A6B1-integrin/laminin 333 complexes. To this end, following immunofluorescence, B1-integrin, laminin G3 (at the A6B1-integrin/laminin 333 interlocks), N-cadherin, B-catenin, P-B-catenin$\mathrm{Tyr}^{654}$ (at the $\mathrm{N}$-cadherin/ $\mathrm{N}$-cadherin interlocks), FAK, P-FAK-Tyr ${ }^{397}$, SRC and P-SRC-Tyr ${ }^{416}$ proteins were localised throughout the eight stages of the seminiferous epithelium cycle and the 13 steps of spermatid differentiation in the comparison between active and regressing testes. Their quantitative variations were evaluated by immunoblotting. We report that massive post-meiotic germ cell sloughing correlates with: (1) in situ altered localisation of B1-integrin, laminin G3, FAK, P-FAK, N-cadherin, B-catenin, P-B-catenin, SRC and P-SRC proteins; (2) decreased quantity of B-catenin, FAK and SRC proteins whereas (3) their phosphorylated forms and B1-integrin levels increased.

\section{Materials and methods}

\section{Testes collection and histology}

Armadillos were caught in the area of Loma Verde $\left(35^{\circ} 16^{\prime} \mathrm{S}\right.$; $58^{\circ} 23^{\prime} \mathrm{W}$; http://g.co/maps/sswm, Province of Buenos Aires, Argentina) during several trapping campaigns from 2008 to 2012. Permissions were given by the Ministerio de Asuntos Agrarios de la Provincia de Buenos Aires. Animal handling was carried out in strict accordance with UK Animals Scientific Procedures Act and approved by the local Comitè Institucional para Cuidado y Uso de Animales de Laboratorio (CICUAL-UM).

From each trapped male, the left testis was withdrawn under anaesthesia (Luaces et al. 2013). Prior to fixation, the tip of the testes was cut and frozen at $-80^{\circ} \mathrm{C}$ for subsequent protein extraction (see 'Immunoblotting analysis' section). Then, the tunica albuginea was carefully and rapidly perforated in different regions with a thin needle and testes dropped in $10 \%$ buffered formalin for $20 \mathrm{~min}$ to let them harden for subsequent cut into transversal slices (about $3 \mathrm{~mm}$ thick) with a sharp razor blade to fasten fixation. Testis slices were kept in the same fixative for further $24 \mathrm{~h}$, washed in tap water, dehydrated through an ascending ethanol series and separately included in paraffin wax. For each animal, three $5 \mu \mathrm{m}$ transverse crosssections from a testis slice were analysed. Testis sections with a diameter larger than $20 \mathrm{~mm}$ were halved and each half was laid onto different slides. Sections were stained with periodic acid-Schiff (PAS)-hematoxylin reaction, useful to visualise the morphology of the developing acrosome (Leblond \& Clermont 1952), as follows: following deparaffinisation, sections were treated with periodic acid $(1 \%$ in distilled water, $6 \mathrm{~min}$ at room temperature, r.t.), rinsed in distilled water, stained with Schiff's reagent $(5 \mathrm{~min}$, r.t.), washed in running tap water (4 times, 5 min each), counterstained with Harris haematoxylin ( $8 \mathrm{~min}$, r.t.), washed in running tap water ( 5 min), differentiated in 1\% acidic alcohol (2 dips), washed in running tap water $(1 \mathrm{~min})$, blued in $0.2 \%$ ammonia water ( $1 \mathrm{~min})$, washed in running tap water $(5 \mathrm{~min})$, immersed in $95 \%$ alcohol (10 dips), in Xylene $(1 \mathrm{~min})$ and mounted in Eukitt. Then, sections were analysed to determine the activity of the spermatogenetic process (Luaces et al. 2013, 2014) in order to select active and regressing testes. Twenty-seven testes were chosen, 13 of which were fully active whereas 14 were in regression. Table 1 reports, for each sample, the animal identification number, the testis activity status and the type of analysis performed. 
Table 1 Animal identification codes, phase of testis activity, and sets of analyses carried out for each individual.

\begin{tabular}{|c|c|c|c|c|}
\hline $\begin{array}{l}\text { Animal } \\
\text { number }\end{array}$ & Testis phase* & Histology & $\begin{array}{c}\text { Immuno- } \\
\text { fluorescence }\end{array}$ & $\begin{array}{l}\text { Immuno- } \\
\text { blotting }\end{array}$ \\
\hline $1024-5$ & Active & $x$ & $x$ & \\
\hline 1024-1 & Active & $x$ & $X$ & $X$ \\
\hline 1044-1 & Active & $x$ & $x$ & $X$ \\
\hline $1060-1$ & Active & $x$ & $x$ & \\
\hline $1060-3$ & Active & $X$ & $X$ & \\
\hline 1029 & Active & $x$ & & $x$ \\
\hline $984 b$ & Active & $x$ & & $x$ \\
\hline $984 a$ & Active & $x$ & & $X$ \\
\hline 1026 & Active & $x$ & & $x$ \\
\hline 978 & Active & $x$ & & $x$ \\
\hline 030 & Active & $X$ & $x$ & \\
\hline 014 & Active & $x$ & $x$ & \\
\hline 013 & Active & $x$ & $x$ & \\
\hline 025 & Regressing, I & $x$ & $x$ & \\
\hline 001 & Regressing, I & $x$ & $x$ & \\
\hline 029 & Regressing, I & $x$ & $x$ & \\
\hline 016 & Regressing, I & $x$ & $X$ & \\
\hline $1051-1$ & Regressing, I & $x$ & & $x$ \\
\hline $1050-3$ & Regressing, I & $x$ & & $x$ \\
\hline $1051-3$ & Regressing, I & $x$ & & $x$ \\
\hline 011 & Regressing, I/II & $x$ & & $x$ \\
\hline 007 & Regressing, I/II & $x$ & $X$ & \\
\hline 028 & Regressing, I/II & $x$ & $X$ & \\
\hline 965 & Regressing, $\mathrm{I} / \mathrm{II}$ & $x$ & & $x$ \\
\hline 960 & Regressing, II & $x$ & & $x$ \\
\hline 002 & Regressing, II/III & $x$ & $X$ & \\
\hline $1050-1$ & Regressing, III & $x$ & & $X$ \\
\hline
\end{tabular}

*Roman numbers refer to the regression phase of the seminiferous epithelium (Luaces et al. 2014).

\section{Immunofluorescence}

As for the histology, $5 \mu \mathrm{m}$ transverse cross-sections were cut from slices of eight active and seven regressing testes (Table 1). One transverse cross section was mounted onto each slide. Testis sections with a diameter larger than $20 \mathrm{~mm}$ were halved and laid onto two slides. For each testis and for each primary antibody (Table 2), immunofluorescence was separately performed onto two independent slides. Antigen retrieval was performed in $10 \mathrm{mM}$ sodium citrate (product no. S4641; Sigma) and 0.05\% Tween 20 (product no. P9416; Sigma), pH 6.0 at $95^{\circ} \mathrm{C}$ for $20 \mathrm{~min}$ (Shi et al. 1993). Then, sections were incubated with $1 \% \mathrm{v} / \mathrm{v}$ Fetal Bovine Serum (FBS, product no. 10270-106; Gibco) in 1× PBS (137 mM NaCl, $2.7 \mathrm{mM} \mathrm{KCl}$, $10 \mathrm{mM} \mathrm{Na} \mathrm{HPO}_{4}$ and $2 \mathrm{mM} \mathrm{KH}_{2} \mathrm{PO}_{4}$ ) for $30 \mathrm{~min}$ at $37^{\circ} \mathrm{C}$ to prevent non-specific binding of the primary antibody. Primary antibodies were applied at the dilutions reported in Table 2 in $1 \% \mathrm{v} / \mathrm{v} \mathrm{FBS} / 1 \times \mathrm{PBS}$ and incubated overnight at $4^{\circ} \mathrm{C}$, with the exception of $\mathrm{B}$-catenin and SRC antibodies that were incubated at $37^{\circ} \mathrm{C}$ for $1 \mathrm{~h}$. After three washes in $1 \times \mathrm{PBS}$, sections were incubated with goat AlexaFluor 555-conjugated anti-rabbit IgG (product no. A21428, Thermo Fisher Scientific) or with sheep Cy3-conjugated anti-mouse (product no. C2181, Sigma) or goat AlexaFluor 633-conjugated anti-rabbit (product no. A-21070, Thermo Fisher Scientific) secondary antibodies diluted $1: 400$ in $1 \% \mathrm{v} / \mathrm{v} \mathrm{FBS} / 1 \times \mathrm{PBS}$ for $30 \mathrm{~min}$ at $37^{\circ} \mathrm{C}$; then slides were washed again, counterstained with $0.1 \mu \mathrm{g} / \mathrm{mL}$ 4',6'-diaminido-2-phenylindole (DAPI; product no. D8417,
Sigma) and mounted with VECTASHIELD Mounting Medium (product no. H-1000; Vector Laboratories). In negative controls, primary antibodies were omitted.

\section{Image analysis}

Histological sections staining with PAS were examined with an Olympus BX60 epifluorescence microscope equipped with a Tango motorised Z-axis (Märzhäuser Wetzlar, Wetzlar, Germany) and digital images were captured (under 100x objective) using an Olympus DP72 digital camera controlled by Olympus CellSens Dimension 1.4.1 software.

Antibody immunofluorescence localisation of SRC, P-SRC, FAK, P-FAK, laminin G3 and P-B-catenin was analysed with a Leica TCS SP5 II confocal microscope equipped with lasers for AlexaFluor 555, Cy3 and DAPI fluorochromes. Antibody immunofluorescence localisation of $\mathrm{N}$-cadherin, B-catenin and B1-integrin was analysed with a Zeiss LSM800 confocal microscope equipped with lasers for AlexaFluor 555, AlexaFluor 633 and DAPI fluorochromes. Stacks were obtained with axial distances of $0.5 \mu \mathrm{m}$.

\section{Immunoblotting analysis}

Seven active and seven regressing testis samples (Table 1) were homogenised in RIPA buffer with protease inhibitors $(150 \mathrm{mM}$ $\mathrm{NaCl}, 5 \mathrm{mM}$ EDTA, pH 8.0, $50 \mathrm{mM}$ Tris-HCl, 1.0\% v/v NP-40 (product no 28324, Thermo Fisher Scientific), 0.5\% sodium deoxycholate, $0.1 \%$ SDS (product no. 71725, Sigma), $5 \mu \mathrm{g} /$ $\mathrm{mL}$ Protease Inhibitor Cocktail (product no. P2714, Sigma)). Protein suspension was centrifuged for $10 \mathrm{~min}$ at $13,000 \mathrm{~g}$ and concentration of proteins in the supernatant was measured using the Bradford's method (Bradford 1976). Ten microgram per sample were mixed with gel loading buffer $(2 \% \mathrm{w} / \mathrm{v}$ SDS in Tris- $\mathrm{HCl}$ ( $\mathrm{pH}$ 8), 25\% glycerol (product no. G7757, Sigma), $1 \% \mathrm{v} / \mathrm{v} 2$-mercaptoethanol (product no. M3148, Sigma) and $0.1 \% \mathrm{w} / \mathrm{v}$ bromophenol blue (product no. B8026, Sigma)). Samples were then denatured for $5 \mathrm{~min}$ at $95^{\circ} \mathrm{C}$ and separated onto $8 \%$ v/v (P-FAK, FAK, B1-integrin, N-cadherin, laminin G3, actin and GAPDH) or $12.5 \%$ v/v (P-B-catenin, B-catenin, P-SRC, SRC, MMP2 and actin) SDS-polyacrylamide mini-gels. After gels were dipped in the transfer buffer $(25 \mathrm{mM}$ Tris- $\mathrm{HCl}$, $192 \mathrm{mM}$ glycine (product no. G8898, Sigma) and 20\% v/v methanol (product no. 322415, Sigma)) for $30 \mathrm{~min}$, proteins were blotted on a nitrocellulose membrane (product no. 162-0145, Bio-Rad Laboratories). Membranes containing the proteins were blocked for $30 \mathrm{~min}$ at room temperature with $3 \%$ bovine serum albumin (BSA, product no. A3311, Sigma) in TBS-T buffer $(2 \mathrm{mM}$ Tris- $\mathrm{HCl}, 13.6 \mathrm{mM} \mathrm{NaCl}$ and $0.1 \% \mathrm{v} / \mathrm{v}$ Tween-20 ( $\mathrm{pH} 7.6))$, in gentle agitation, and then incubated for $2 \mathrm{~h}$ at $37^{\circ} \mathrm{C}$ with the primary antibodies, diluted in TBS-T buffer (for antibody concentration see Table 1). After washing with TBS-T buffer, the membranes were incubated with goat HRP conjugated anti-rabbit (product no. A9169, Sigma) (for B1-integrin, P-FAK, FAK, B-catenin, P-B-catenin, SRC, MMP-2, $\mathrm{N}$-cadherin, laminin G3 and GAPDH) or goat HRP-conjugated anti-mouse (product no. F21453, Molecular Probes; for p-SRC) IgG antibodies for $30 \mathrm{~min}$ at $37^{\circ} \mathrm{C}$, using a $1: 25,000$ dilution in TBS-T buffer, in gentle agitation, and then washed 
Table 2 Primary antibodies used, their source, application and dilution.

\begin{tabular}{|c|c|c|c|}
\hline Antibody & Source & Catalogue number & Application and dilution \\
\hline Rabbit anti-human integrin-B1 & Merck Millipore & 1952 & $\begin{array}{l}\text { IF }(1: 100) \\
\text { IB }(1: 5000)\end{array}$ \\
\hline Rabbit anti-human FAK & Cell Signalling & 3285 & $\begin{array}{l}\text { IF (1:100) } \\
\text { IB }(1: 5000)\end{array}$ \\
\hline Rabbit anti-human phospho-FAK (Tyr397) & Cell Signalling & 3283 & $\begin{array}{l}\text { IF }(1: 50) \\
\text { IB }(1: 5000)\end{array}$ \\
\hline Rabbit anti-human SRC & Cell Signalling & 2108 & $\begin{array}{l}\text { IF }(1: 200) \\
\text { IB }(1: 5000)\end{array}$ \\
\hline Mouse anti-avian phospho-SRC (Tyr416) & Merck Millipore & $05-677$ & $\begin{array}{l}\text { IF (1:50) } \\
\text { IB }(1: 5000)\end{array}$ \\
\hline Rabbit anti-human MMP2 & Abcam & 79781 & IB $(1: 5000)$ \\
\hline Rabbit anti-human B-catenin & Abcam & 32572 & $\begin{array}{l}\text { IF }(1: 250) \\
\text { IB }(1: 5000)\end{array}$ \\
\hline Rabbit anti-human $\mathrm{N}$-cadherin & Abcam & 12221 & $\begin{array}{l}\text { IF }(1: 100) \\
\text { IB }(1: 2000)\end{array}$ \\
\hline Rabbit anti-human phospho-B-catenin (Tyr654) & ECM Biosciences & 4021 & $\begin{array}{l}\text { IF }(1: 50) \\
\text { IB }(1: 5000)\end{array}$ \\
\hline Mouse anti-mouse laminin G3 & Santa Cruz Biotechnology & 517444 & IB $(1: 2000)$ \\
\hline Rabbit anti-human laminin G3 & Thermo Fisher Scientific & PA5-38939 & IF $(1: 200)$ \\
\hline Goat anti-human actin, HRP conjugated & Santa Cruz Biotechnology & 1615-HRP & IB $(1: 10,000)$ \\
\hline Rabbit anti-human GAPDH & GeneTex & 100118 & IB $(1: 5000)$ \\
\hline
\end{tabular}

IB, immunoblotting; IF, immunofluorescence microscopy.

thoroughly. Chemiluminescent detection was performed using the Westar Supernova (product no. XLS3, Cyanagen), suitable for low fentogram samples, according to the manufacturers' instructions that recommend a primary antibody dilution between 1:5000 and 1:100,000.

For each antibody used, species cross-reactivity was determined by Western blot comparison between armadillo protein extracts and those obtained from the species to which antibodies were raised or cross-react (as detailed in the manufacturers' datasheets).

Since immunoblotting of GAPDH and actin proteins did not show any different quantitative expression in the comparison between active and regressive testes ( $n=3$ for each condition, data not shown), we used the latter protein as loading control. Moreover, being equally expressed $(P=0.787)$ in both active and regressing animals, actin was used to normalise the expression of target proteins. The chemiluminescent blots were imaged with ChemiDoc XRS system (Bio-Rad) and acquired with the Quantity One software (Bio-Rad). Densitometric intensities of the bands were determined with ImageJ software (Schneider et al. 2012).

\section{Statistical analysis}

Statistical analyses were carried out using Sigma Stat 3.0 software. After immunoblotting, Imagel software was used to quantify the intensity of protein bands, and data were expressed as arbitrary units of pixel density following normalisation on actin. For each protein, at least five animals per active or regressing group were analysed.

The one-way ANOVA was used for intra- and inter-group comparisons when the values of protein expression were normally distributed. The non-parametric Mann-Whitney test was used when protein expression values were not normally distributed. Non-parametric data are expressed as the median and first and third quartiles (25\% and 75\%). For each target protein, fold-change (FC) variations of the mean of normalised values in regressing compared to active testes were determined.

\section{Results}

Following the criteria for stage identification described earlier in Luaces et al. (2013), B1-integrin, laminin G3, N-cadherin, FAK, P-FAK-Tyr ${ }^{397}$, SRC, P-SRC-Tyr ${ }^{416}$, B-catenin and P-B-catenin-Tyr ${ }^{654}$ proteins were first localised in active testes throughout the eight stages of the cycle of the seminiferous epithelium. Then, the same proteins were mapped in the seminiferous epithelium of regressing testes.

\section{B1-integrin and laminin G3}

The A6B1-integrin/laminin 333 interlocks are among the multiprotein complexes present at the apical ES-associated AJ structures. B1-integrin is an integral membrane protein of the Sertoli cells that associates, on the cytoplasm side, with the FAK/C-SRC complex to make a cell matrix focal adhesion-like structure (Siu et al. 2011). In the extracellular compartment, it binds to the laminin 333 (A3, B3 and G3 chains) complex present on the elongating/elongated spermatids membrane (Siu \& Cheng 2004, Yan \& Cheng 2006). In the armadillo, B1-integrin and laminin G3 immunofluorescence (Fig. 1) localise at the head of round (Fig. $1 \mathrm{k}-\mathrm{k}^{\mathrm{i}}$ and $\mathrm{s}-\mathrm{s}^{\mathrm{i}}$, respectively; arrowheads) and elongating (Fig. $1 \mathrm{i}-\mathrm{j}^{\mathrm{i}}$ and $\left.n-x^{i}\right)$ spermatids, until when mature spermatids are released into the tubule lumen (stage $\mathrm{V}$ ) (Fig. $1 \mathrm{~m}-\mathrm{m}^{\mathrm{i}}$ and $\left.\mathrm{u}-\mathrm{u}^{\mathrm{i}}\right)$. Stage I and II round spermatids are negative (Fig. $1 \mathrm{i}-\mathrm{j}^{\mathrm{i}}$ and $\mathrm{q}-\mathrm{r}^{\mathrm{i}}$ ). 


\section{FAK and P-FAK-Tyr ${ }^{397}$}

FAK is a cytoplasmic non-receptor protein kinase expressed by both Sertoli and germ cells, mainly localised at the blood-testis barrier (BTB) near the basal membrane, and a modulator of the tight junctions (TJ) integrity. The downregulation or upregulation of its expression, together with its phosphorylation status at $\mathrm{Tyr}^{407}$, timely regulates the dismantlement or reconstitution of the blood-testis barrier (BTB) (Siu et al. 2009, Lie et al. 2012). In the seminiferous epithelium of C. villosus, FAK immunosignals localise in the basal compartment with a clear diffused pattern around spermatogonia (Fig. 2a-hi, empty arrowheads), throughout the eight stages of the cycle, in accordance with its presence in the TJ at the BTB.

Next, we examined the localisation of the FAK phosphorylated form at $\mathrm{Tyr}^{397}$ (P-FAK). FAK autophosphorylation is involved in the separation of the FAK-integrin complex at the A6B1-integrin/laminin G3 interlocks and contributes to the disassembly of the apical ES (Beardsley \& O'Donnell 2003, Beardsley et al. 2006,

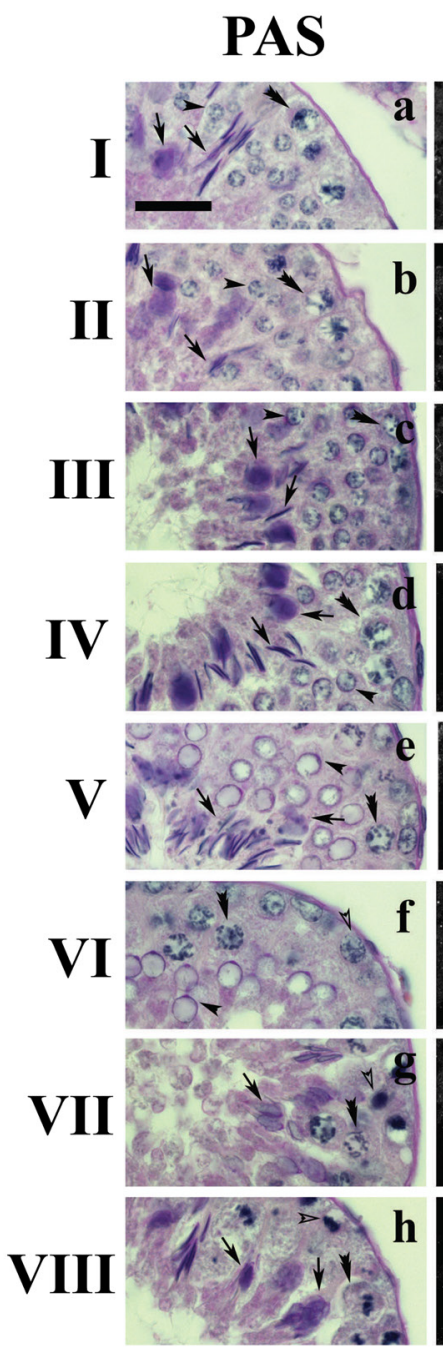

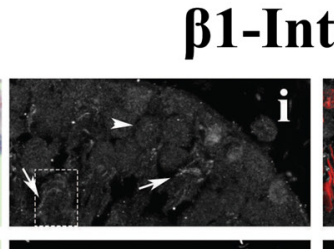

B1-Integrin
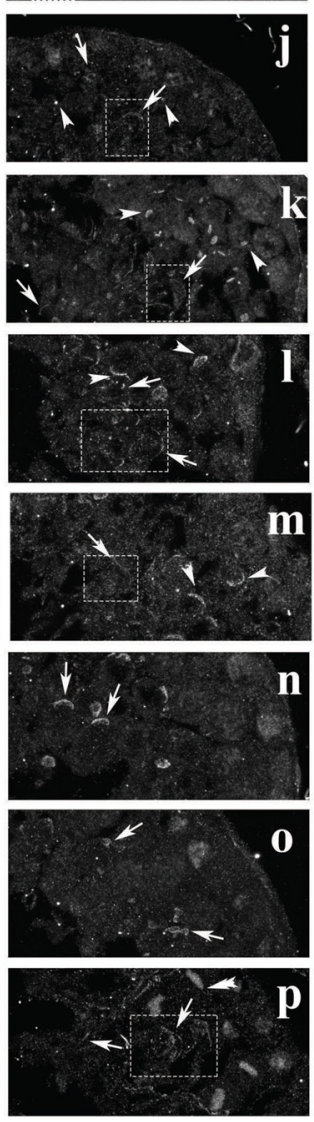
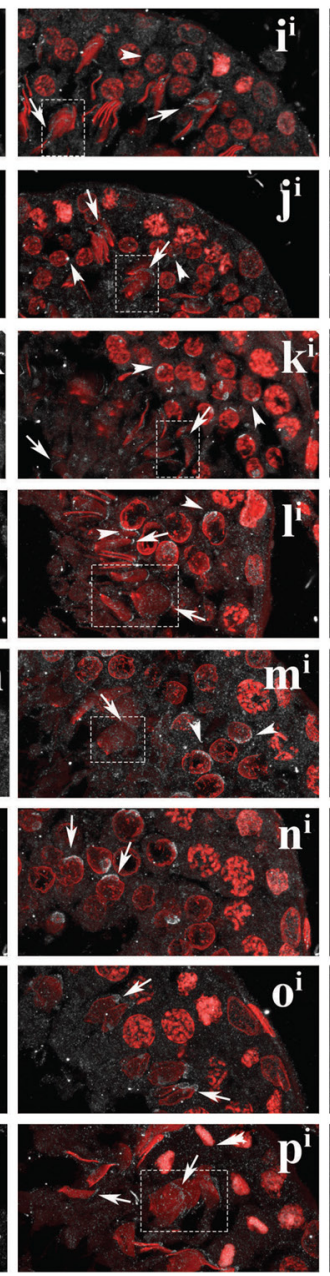
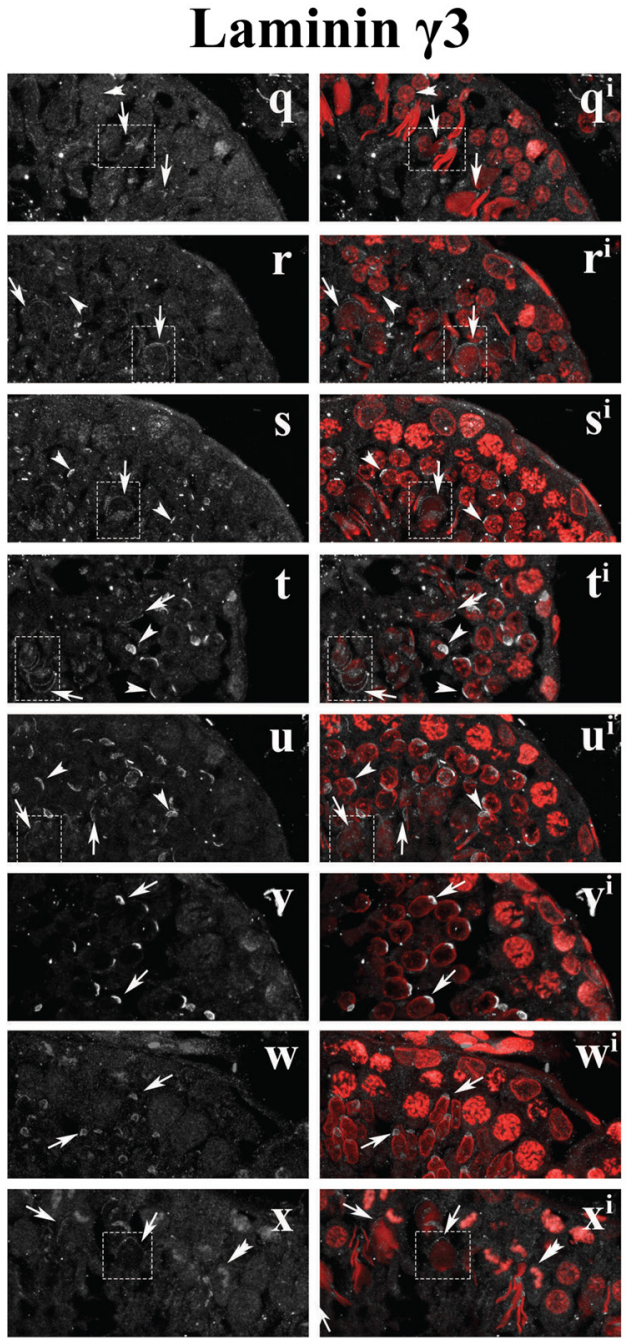

Figure 1 Periodic acid-Schiff-hematoxylin (PAS, a-h) of cross-sections depicting the eight stages (annotated with Roman numeral) of the cycle of the seminiferous epithelium in active testes. The eight stages are defined by characteristic cell-specific associations, the progressive changes of spermatid nuclei shape and the acrosome formation (magenta staining) (Luaces et al. 2013). During spermiogenesis, spermatid nuclei acquire a characteristic spoon-like shape, very large in size and extremely thin (Cetica et al. 1998). The loosely packed chromatin (Luaces et al. 2013) within a large and flat nucleus results in very dim DAPI fluorescence (red pseudocolor). Confocal images of anti-B1-integrin (i-p) and anti-laminin G3 $(q-x)$ immunofluorescence staining; nuclei are counterstained with DAPI (red pseudocolor) and merged with the corresponding immunofluorescence images $\left(i^{i}-p^{i}\right)$ and $\left(q^{i}-x^{i}\right)$. The signal is present, as a small rod, at stage III round spermatid heads $\left(k-k^{i}\right.$ and $s-s^{i}$, respectively; arrowheads). Then, it progressively extends and, at stage VIII, a thin thread outlines the anterior-lateral head region of elongating spermatids ( $\mathrm{p}-\mathrm{p}^{\mathrm{i}}$, $\mathrm{x}-\mathrm{x}^{\mathrm{i}}$, arrows). The same pattern is maintained until when mature spermatids are released into the tubule lumen (stage $\mathrm{V}$ ) ( $\mathrm{m}-\mathrm{m}^{\mathrm{i}}$, $\mathrm{u}-\mathrm{u}^{\mathrm{i}}$, arrows). Stage I and II round spermatids were negative (i-ji; $q-r^{i}$, arrowheads). The signal is also positive at metaphase spermatocytes ( $p-p^{i}, x-x^{i}$, arrowheads). Spermatogonia, empty arrowheads. Spermatocytes, double arrowheads. round spermatids, arrowheads; elongating spermatids, arrows. Bar, $20 \mu$ m. 
Lie et al. 2012, Wan et al. 2014). In the seminiferous epithelium of C. villosus, P-FAK immunolabeling is restricted to stages III-V (Fig. $2 \mathrm{k}-\mathrm{m}^{\mathrm{i}}$ ), where it is diffused in both basal and adluminal compartments with higher intensity at step 13 elongated spermatids (Fig. 2m$\mathrm{m}^{\mathrm{i}}$, arrows), the latter ready to be released into the tubule lumen.

\section{N-cadherin, B-catenin and P-B-catenin-Tyr ${ }^{654}$}

In the testis, $\mathrm{N}$-cadherin is a calcium-dependent cell-cell integral membrane adhesion glycoprotein that associates with its cytoplasmic interacting partner, B-catenin, to form the actin-linked $\mathrm{N}$-cadherin/B-catenin complex of the cadherin/cadherin interlocks (Zhang et al. 2005, Lui \& Lee 2009). These interlocks contribute to the AJ stability present at both apical and basal ES (Salanova et al. 1995, Ozaki-Kuroda et al. 2002, Lee et al. 2003, Siu et al. 2003, 2011, Gliki et al. 2004).

In the armadillo, using double immunolabeling with anti-N-cadherin and anti-B-catenin antibodies, fluorescence signals were always found to co-localise at spermatogonia (Fig. 3a-hii, empty arrowheads), spermatocytes (double arrowheads) and elongating/ elongated spermatids (arrows) throughout the eight stages of the seminiferous epithelium cycle. Both signals co-localise also at pre-leptotene (stage VI, Fig. 3f-fii, empty arrows) and leptotene (stage VII, Fig. 3g-gii, empty arrows) spermatocytes and, from stage III, at round spermatids (Fig. 3e-e $\mathrm{e}^{\mathrm{ii}}$, arrowheads).

Since a surge of Tyr ${ }^{654}$ phosphorylation of B-catenin (P-B-catenin), likely induced by the SRC kinase activity (Zhang et al. 2005), has been associated, in the rat, with loss of $\mathrm{N}$-cadherin-B-catenin bonds followed by germ cell detachment (Zhang et al. 2005), the localisation of this phosphorylated form was performed to verify its presence at the Sertoli cell/spermatid junctions. P-Bcatenin immunostaining is negative at round spermatids (Fig. $3 \mathrm{~b}-\mathrm{j}^{\mathrm{i}}$, arrowheads) and at stage VI elongating spermatids (Fig. $\left.3 \mid-I^{i}\right)$; then, it becomes positive at the tip of stage VII elongating spermatids (Fig. $3 n-n^{i}$, arrows) and, progressively, it decorates the elongating spermatid heads (Fig. 3b-ji, arrows) until when, at stage VI, elongated spermatids are released into the tubule lumen.

\section{SRC and P-SRC-Tyr ${ }^{416}$}

SRC, a non-receptor protein tyrosine kinase member of the SRC family, is a binding partner of FAK at the A6B1integrin/laminin G3 interlocks (Yan \& Cheng 2006) and of catenin at the cadherin/catenin complexes (Lee \& Cheng 2005), where it modulates the phosphorylation status of several proteins (Zhang et al. 2005, Lie et al. 2010).

In the active large hairy armadillo testis, SRC diffuse signals localise within the Sertoli cell cytoplasm and brightly contour germ cells in both the basal and adluminal compartments throughout the eight stages of the cycle of the seminiferous epithelium (Fig. 4a$\left.h^{i}\right)$. Since SRC autophosphorylation contributes to the detachment of the activated FAK/c-SRC complex from integrins (Wong et al. 2008), we analysed its phosphorylated form at Tyr ${ }^{416}$ (P-SRC). P-SRC showed a stage-specific distribution, stages IV (Fig. 4I-I') and $V$ (Fig. $4 \mathrm{~m}-\mathrm{m}^{\mathrm{i}}$ ), with signals localised at elongated spermatids (arrows).

After having defined the localisation profiles of these proteins in active testes, we analysed individuals at the initial phases of testis regression, when premature postmeiotic cells are detached, but still present, in the tubule lumen (Luaces et al. 2014).

\section{Apical ES dynamics in the seminiferous epithelium of regressing testes}

Armadillo testis regression entails four phases of progressive cell depletion, which initiates with round spermatids prematurely detached (phase I) and released into the lumen leading to massive desquamation (phase II). Then, spermatocytes are eliminated through apoptosis (phase III) and regression ends with the sole Sertoli cells and spermatogonia remaining in the seminiferous epithelium (phase IV) (Luaces et al. 2014).

Proteins were localised in the seminiferous epithelium during the desquamation process occurring at phases I and II (Figs 5, 6, 7 and 8) and their quantitative expression was compared in regressing vs active testes (Fig. 9).

\section{B1-integrin and laminin G3}

At both regression phase I (Fig. 5a-C) and II (Fig. 5d), diffused B1-integrin signals are visible at both basal and antral compartments. Thin immunofluorescent threads decorate the head of elongated spermatids (arrows) from stage I to $\mathrm{V}$ at regression phase I (Fig. $5 \mathrm{e}-\mathrm{f}^{\mathrm{i}}$ ) and at regression phase II (Fig. $5 \mathrm{~h}$ and $\mathrm{h}^{\mathrm{i}}$ ). The same pattern was detected when using an anti-laminin G3 antibody (Fig. $5 \mathrm{i}-\mathrm{I}^{\mathrm{i}}$ ).

When compared to active, B1-integrin expression was 7.06-fold upregulated in regressing testes (Fig. 9B), showing a significantly $(P=0.022)$ higher value (median value, $M=2.87$ and $M=0.48$, regressing vs active testes) (Fig. 9A). Laminin G3 was also 1.97 upregulated in regressing (median value, $M=1.5$ ) vs active (median value, $M=0.79$ ) testes, although without statistical significance ( $P=0.062 ;$ Fig. $9 \mathrm{~A}$ and $\mathrm{B})$. Since, in the rat, a surge of MMP2 has been described at the time of spermiation, and it has been found to co-localise with laminin G3 at the apical ES (Siu \& Cheng 2004), we questioned whether its quantitative level might increase during the massive release of immature post-meiotic cells in regressing testes. In fact, significantly $(P=0.010)$ higher levels of proteins were measured in regressing $(M=0.42)$ compared to active $(M=0.14)$ testes (Fig. 9A), with a FC increase of 3.69 (Fig. 9B). 


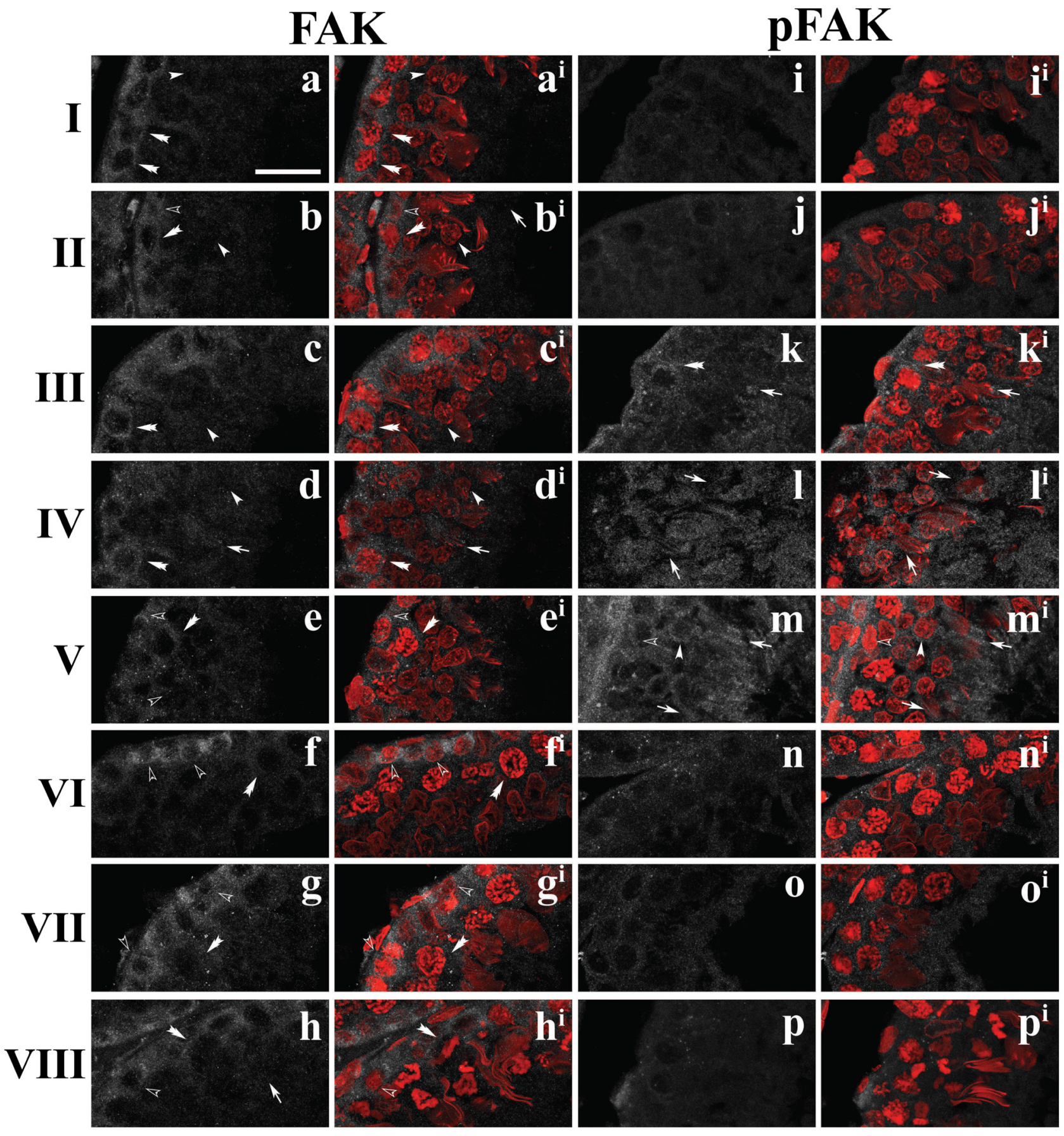

Figure 2 Confocal images of anti-FAK ( $a-h)$ and anti-P-FAK (i-p) immunofluorescence staining on cross-sections representative of the eight stages (annotated with Roman numeral) of the cycle of the seminiferous epithelium in active testes. Nuclei are counterstained with DAPI (red pseudocolor) and merged with the corresponding immunofluorescence images $\left(\mathrm{a}^{\mathrm{i}}-\mathrm{h}^{\mathrm{i}}\right.$ and $\left.\mathrm{i}^{\mathrm{i}}-\mathrm{p}^{\mathrm{i}}\right)$. FAK signals are present at the basal compartment throughout the eight stages of the seminiferous epithelium cycle. Post-meiotic cells are always negative (arrows and arrowheads). P-FAK-Tyr ${ }^{397}$ is temporally detected only at stages III-V $\left(\mathrm{k}-\mathrm{m}^{\mathrm{i}}\right)$. Signals are visible at the basal compartment (empty arrowheads), at spermatocytes (double arrowheads) at stages IV and $\mathrm{V}$ and at round spermatids ( $\mathrm{m}-\mathrm{m}^{\mathrm{i}}$, arrowheads) at stage $\mathrm{V}$. The signals contour elongated spermatids (arrows) with higher intensity at stage $V\left(m-m^{i}\right)$. Cells at stages $I-I I\left(i-j^{i}\right)$ and $V I-V I I I ~\left(n-p^{i}\right)$ are negative to the immunoreaction.

\section{FAK and P-FAK}

At regression phase I, FAK immunofluorescence showed diffused signals localised at the basal compartment at the BTB region from stage I to VIII (Fig. 6a-ci, empty arrowheads) spreading towards spermatocytes only at stages VI-VIII (Fig. 6c-Ci, double arrowheads). Both round and elongated spermatids were always negative 


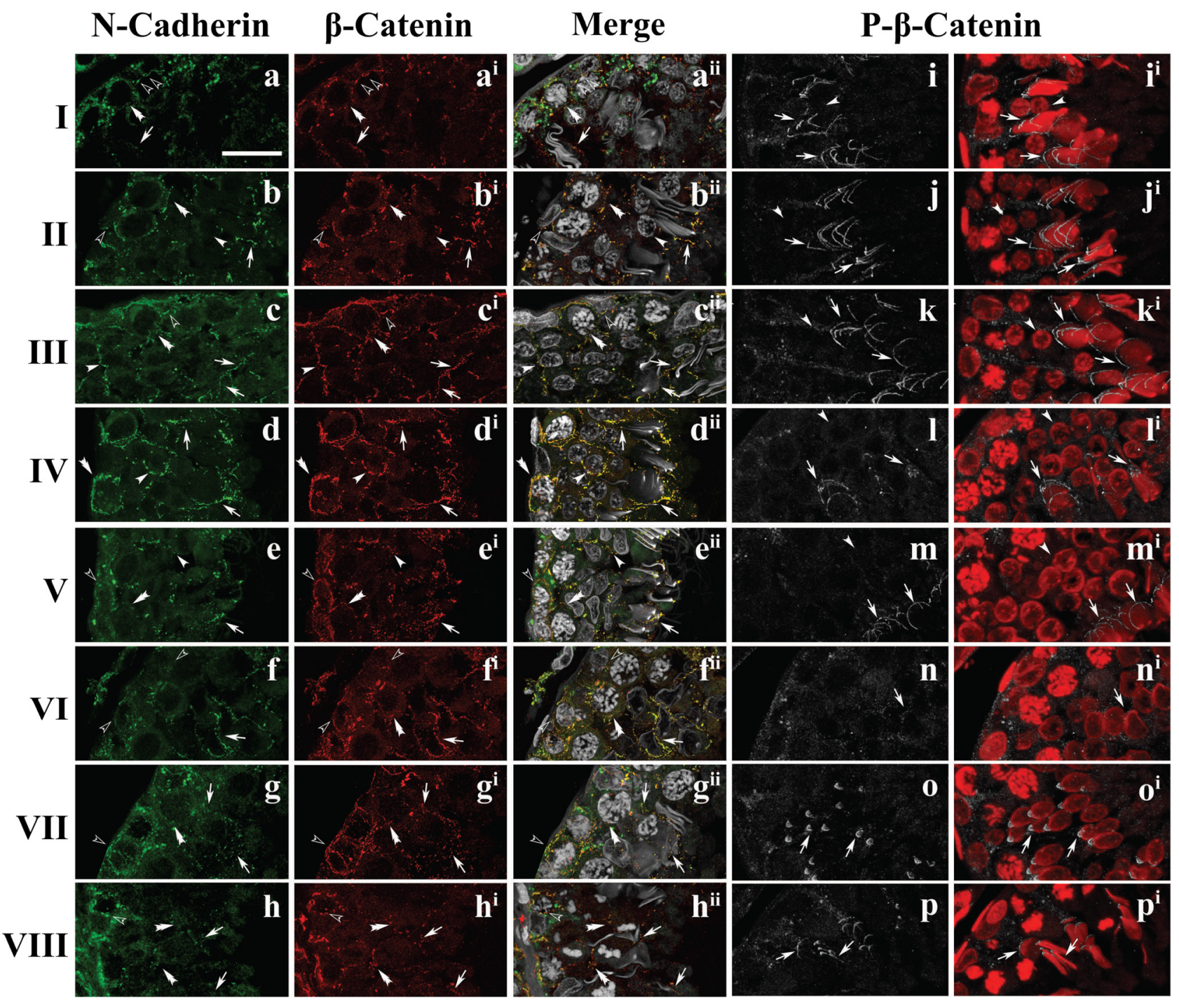

Figure 3 Confocal images of anti-N-cadherin (green), anti-B-catenin (red) and anti-P-B-catenin-Tyr ${ }^{654}$ (white) immunofluorescence staining on

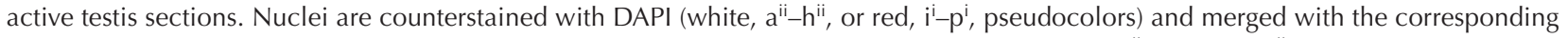
immunofluorescence images. N-cadherin and B-catenin signals always co-localise. At stages I (a-aii) and II (c- $\left.\mathrm{C}^{\mathrm{ii}}\right)$, immunofluorescent signals are detectable at spermatogonia (empty arrowhead), spermatocytes (double arrowheads) and elongating spermatids (arrows) whereas they are undetectable at round spermatids (arrowheads). At stage III (e- $\mathrm{e}^{\mathrm{ii}}$ ), the signals mark both the Sertoli cell stalks at round (arrowheads) and elongating (arrows) spermatids. The same pattern is present at stage IV $\left(\mathrm{g}-\mathrm{g}^{\mathrm{ii}}\right)$. At stage $\mathrm{V}\left(\mathrm{i}-\mathrm{i}^{\mathrm{i}}\right)$, the signal remains strong at the basal compartment, marking spermatogonia (empty arrowhead), spermatocytes (double arrowheads), round (arrowheads) and elongated spermatids (arrows). At stages VI ( $\left.k-\mathrm{k}^{\mathrm{ii}}\right)$ and VII $\left(\mathrm{m}-\mathrm{m}^{\mathrm{ii}}\right)$, immunofluorescence is delineating both pre-leptotene (empty arrows, bottom left) and leptotene (empty arrows) spermatocytes. At stage VIII (o-Oii), co-localised signals are present at MI and MII spermatocytes (double arrowheads). P-B-catenin-Tyr ${ }^{554}$. Round ( $\mathrm{b}-\mathrm{j}^{\mathrm{i}}$, arrowheads), from stage I to stage $\mathrm{V}$, and elongating spermatids $\left(\mathrm{I}-\mathrm{I}^{\mathrm{i}}\right)$ at stage $\mathrm{VI}$ are negative to the immunostaining. At stage VII, the head tips of step 7 elongating spermatids ( $n-n^{i}$, arrows) become brightly decorated. At stage VIII, a threadlike signal extends from the anterior tip of the spermatid heads ( $p-p^{i}$, arrows) and elongates towards the opposite pole (b-ji) until when, at stage $\mathrm{V}$, elongated spermatids are ready to be released into the lumen. The stages of the cycle of the seminiferous epithelium are annotated with Roman numeral. Bar, $20 \mu \mathrm{m}$.

(Fig. 2a-Ci). At regression phase II, the basal compartment was evidenced by diffused dim fluorescence (Fig. 6d-di, empty arrowheads). A 3.07-fold downregulation (Fig. 9B) was measured in regressing testes that had significantly $(P=0.035)$ less relative protein expression $(M=0.19)$ compared to active $(M=0.42)$ testes (Fig. 9A).
Instead, P-FAK protein level was higher in regressing $(M=1.08)$ compared to active $(M=0.50)$ testes $(P=0.001)$ (Fig. 9A), with a FC of 2.46 (Fig. 9B). When mapped on histological sections, at regression phase I, P-FAK dim signals were diffused at the basal compartment from stage I to stage $V$ (Fig. 6e-fi, empty 


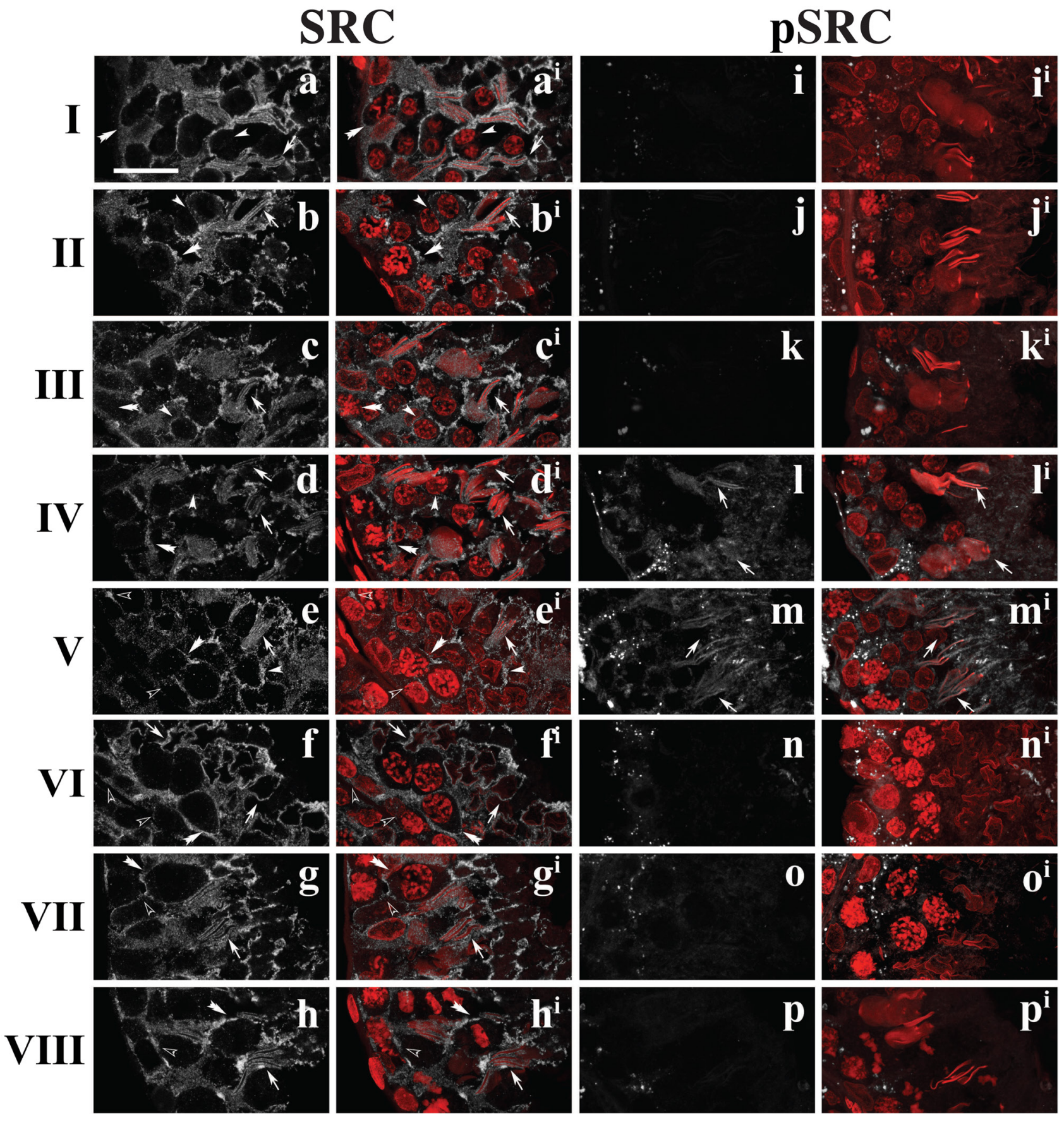

Figure 4 Confocal images of anti-SRC ( $\mathrm{a}-\mathrm{h})$ and anti-P-SRC (i-p) immunofluorescence staining on active testis section. Nuclei are counterstained with DAPI (red pseudocolor) and merged with the corresponding immunofluorescence images $\left(\mathrm{a}^{\mathrm{i}}-\mathrm{h}^{\mathrm{i}}\right.$ and $\left.\mathrm{i}-\mathrm{p}^{\mathrm{i}}\right)$. From stage I (a-ai) to stage $\mathrm{VIII}$ $\left(\mathrm{h}-\mathrm{h}^{\mathrm{i}}\right)$ diffused SRC immunofluorescence is visible from the basal compartment to the lumen, located in the Sertoli cells cytoplasm surrounding spermatocytes (double arrowhead), round (arrowheads) and elongating (arrows) spermatids. At stages $V\left(e-e^{i}\right)$ and $V I\left(f-f^{i}\right)$ the immunosignal stains spermatogonia (empty arrowheads); at stage VII leptotene (g-gi, empty arrowheads) and at stage VIII zygotene (h-hi, empty arrowhead) spermatocytes. P-SRC-Tyr ${ }^{416}$. Stages I-III $\left(i-k^{i}\right)$ and VI-VIII $\left(n-p^{i}\right)$ are negative to the immunostaining. At both stages IV $\left(I-l^{i}\right)$ and V $\left(m-m^{i}\right)$, fluorescence is localised at the adluminal compartment, surrounding the head of elongated spermatids (arrows) and protruding towards the lumen of the tubule with a rod-like shape. The stages of the cycle of the seminiferous epithelium are annotated with Roman numeral. Bar, $20 \mu \mathrm{m}$.

arrowheads). At stages VI-VIII, bright signals localise at the tip of elongating spermatids (Fig. 6g-gi, arrows). At regression phase II, P-FAK immunofluorescence is negative (Fig. $2 \mathrm{~h}-\mathrm{h}^{\mathrm{i}}$ ).

\section{N-cadherin, B-catenin and P-B-catenin-Tyr ${ }^{654}$}

At regression phase I, N-cadherin and B-catenin signals co-localise at spermatocytes (Fig. 7a-cii, double 


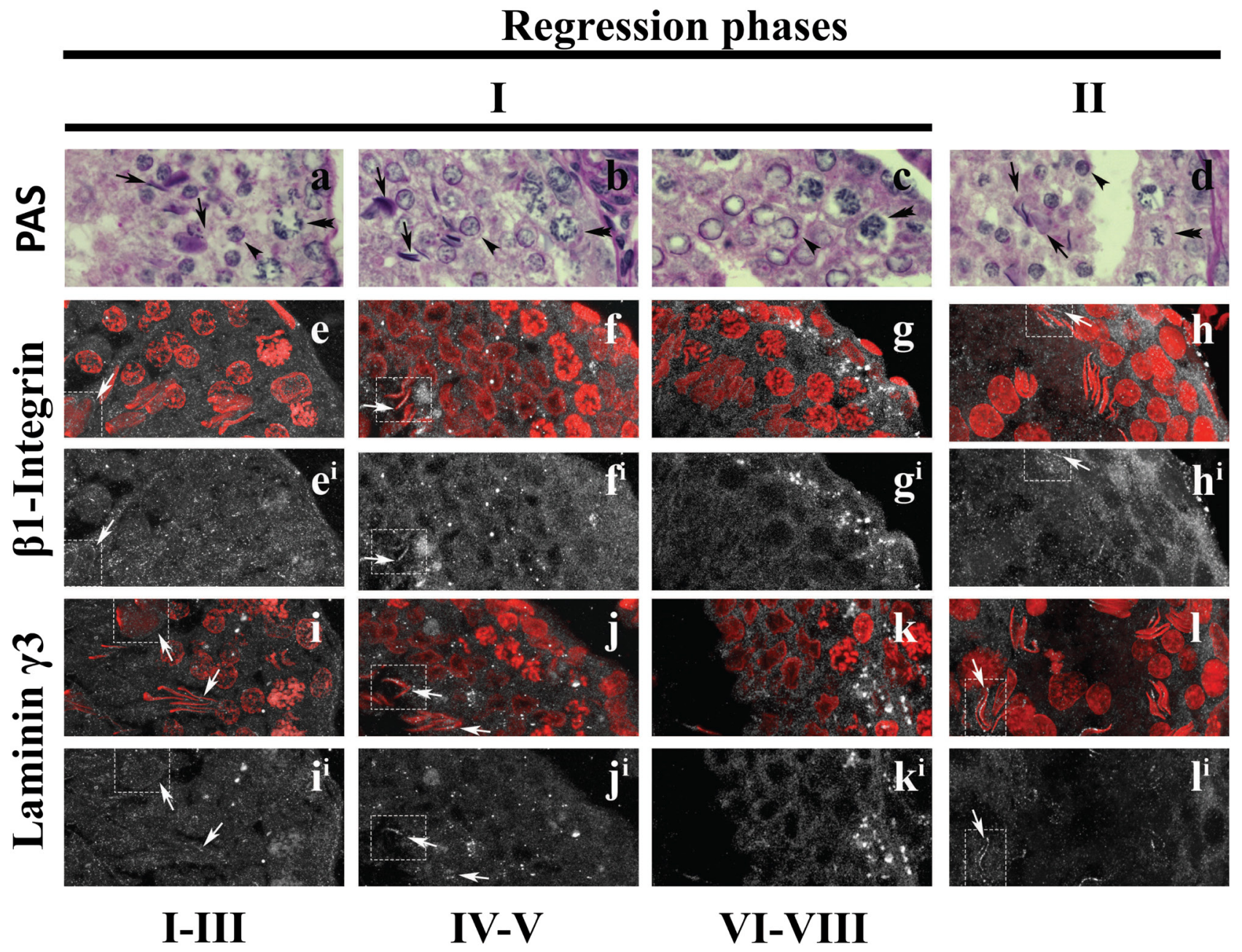

Figure 5 Testis section stained with Periodic acid-Schiff-hematoxylin (PAS, a-d). At the onset of the process, regression phase I, epithelium dysregulation and cell detachment determine alterations of the typical cell associations that impede the precise identification of each stage of the cycle (annotated with Roman numeral). For this reason, the eight stages were grouped in representative categories (a-c). At regression phase II (d), consistent cell sloughing made stage assignment impossible. Confocal images of anti-B-integrin (e $\mathrm{e}^{\mathrm{i}} \mathrm{h}$ ) and anti-laminin G3 (i-li) immunofluorescence staining on testis sections during regression phase I (a-c) and II (d). Nuclei are counterstained with DAPI (red pseudocolor) and merged with the corresponding immunofluorescence images (e-h and $\mathrm{i}-\mathrm{I}$ ). At both regression phase I and II, B1-integrin and laminin G3 confocal images show diffused signals from the basal to the adluminal compartment. Only elongated spermatid heads (arrows, squared nuclei) are still decorated with a thin fluorescence thread. Nuclei are counterstained with DAPI (red pseudocolor). Spermatocytes, double arrowheads; round spermatids, arrowheads; elongating spermatids, arrows. Bar, $20 \mu \mathrm{m}$.

arrowheads) throughout the stages of the seminiferous epithelium cycle. They also co-localise at elongating spermatids from stage I to stage $\mathrm{V}$ (Fig. $7 \mathrm{a}-\mathrm{b}^{\mathrm{i}}$, arrows) and at round spermatids at stages IV-V (Fig. 7b- $b^{i}$, arrowheads). Spermatids at stages VI-VIII are negative (Fig. $7 \mathrm{C}-\mathrm{C}^{\mathrm{ii}}$, arrows). Compared to active testes (Fig. 5), the pattern of $\mathrm{N}$-cadherin localisation is more diffused at stages I-III (Fig. 7a and aii). At regression phase II, $\mathrm{N}$-cadherin and B-catenin co-localise at leptotene and pachytene spermatocytes (Fig. $7 \mathrm{~d}-\mathrm{d}^{\mathrm{ii}}$, empty arrows and double arrowheads, respectively) and at elongated spermatocytes (Fig. 7d-dii, arrows). Desquamated round spermatocytes are also positive (arrowheads). Positive $\mathrm{P}$-B-catenin signals mark the elongating spermatid heads at both regression phase I and II (Fig. 7e-hi, arrows).
Both $\mathrm{N}$-cadherin and B-catenin protein levels decrease $(-1.4$ and -2.67 -folds, respectively) in regressing ( $M=0.12$ and $M=0.45$, respectively) compared to active ( $M=0.18, M=1.21$, respectively) testes, although those of $\mathrm{N}$-cadherin were not significantly different $(P=0.057$; Fig. 9A and B). Instead, P-B-catenin protein level was 3.05 -fold increased in regressing testes $(M=0.13$ and $M=0.07$ in regressing and active testes, respectively, $P=0.035)$.

\section{SRC and P-SRC}

At regression phase I, SRC immunofluorescence contours spermatogonia (Fig. $8 \mathrm{a}-\mathrm{c}^{\mathrm{i}}$, arrows), spermatocytes (Fig. 8a-Ci, double arrowheads), round 


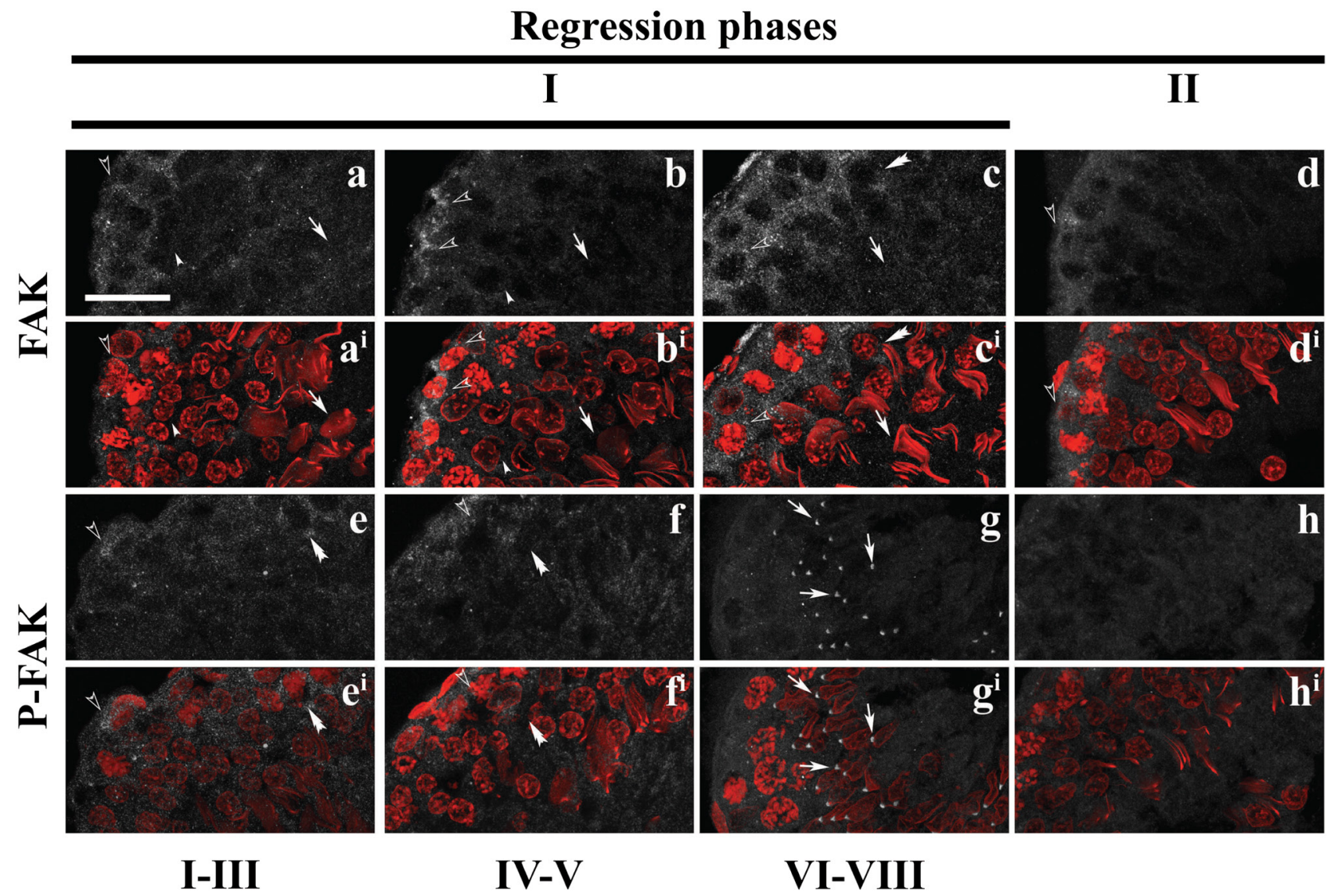

Figure 6 Confocal images of anti-FAK (a-d) and anti-P-FAK $(\mathrm{e}-\mathrm{h})$ immunofluorescence staining of testis sections during regression phase I and II. Nuclei are counterstained with DAPI (red pseudocolor) and merged with the corresponding immunofluorescence images ( $\mathrm{a}^{\mathrm{i}}-\mathrm{d}^{\mathrm{i}}$ and $\left.\mathrm{e}^{\mathrm{i}}-\mathrm{h}^{\mathrm{i}}\right)$. At regression phase I, FAK immunostaining is positive at the basal compartments marking spermatogonia (empty arrows). Diffused signals projects also towards spermatocytes ( $\mathrm{C}-\mathrm{C}^{\mathrm{i}}$, double arrowheads) at stages VI-VIII. At regression phase II, very dim signals are present at the basal compartment $\left(\mathrm{d}-\mathrm{d}^{\mathrm{i}}\right)$. At regression phase I, dim P-FAK immunofluorescence is present at the basal (e-fi, empty arrowheads) and, more dispersed, at the adluminal (e-fi, double arrowheads) compartment at stages I-V; whereas very bright signals are visible at the tip of elongating spermatid heads (arrows, $\left.g-g^{i}\right)$. P-FAK immunostaining is negative at regression phase II $\left(h-h^{i}\right)$. The stages of the seminiferous epithelium cycle are annotated with Roman numeral. Bar, $20 \mu \mathrm{m}$.

(Fig. 8a-bi, arrowheads) and elongated spermatids (Fig. 8a-ci, arrows), cells throughout the cycle stages. The same pattern is maintained at regression phase II (Fig. 8d- $\mathrm{d}^{\mathrm{i}}$ ), although with more diffused signals. Furthermore, the expression of this kinase is lower in regressing $(M=0.20)$ compared to active $(M=0.37)$ testes $(P=0.014 ; \mathrm{FC}=-2.11)$ (Fig. 9A). Instead, the level of its phosphorylated form (P-SRC) is 4.11-fold (Fig. 9B) higher in regressing $(M=1.18)$ compared to active $(M=0.36)$ testes $(P=0.008)$ (Fig. 9A). At regression phase I, P-SRC immunofluorescence (Fig. 8e-gi) has a very similar distribution of its non-phosphorylated form. At regression phase II, the signal becomes much brighter and diffused (Fig. 8h-hi).

\section{Discussion}

In seasonal reproducers, the mechanisms regulating the process of germ cell desquamation during testis regression is still poorly known. These wild animals have strong hormonal response to the natural succession of breeding and non-breeding seasons, showing, during the non-breeding season, very low circulating and intra-testicular testosterone levels (for a review, Jimenez et al. 2015). Both testosterone and gonadotropins are known to regulate the expression of cell adhesion proteins in the testis (Xia et al. 2005, Tarulli et al. 2008, McCabe et al. 2010) and, in testosteronesuppressing experiments in the rat, it has been shown that dissociation of the adhesion complexes at the apical ES contributes to the massive sloughing of immature spermatids (Zhang et al. 2005). Similarly, in armadillo regressing testes, immature spermatid release occurs under low testosterone levels (Luaces et al. 2013). In the present study, we provide evidence that the localisation and quantity of proteins of adhesion complexes present at the apical ES change during testes regression, likely compromising the integrity of the apical ES, resulting 


\section{Regression phases}

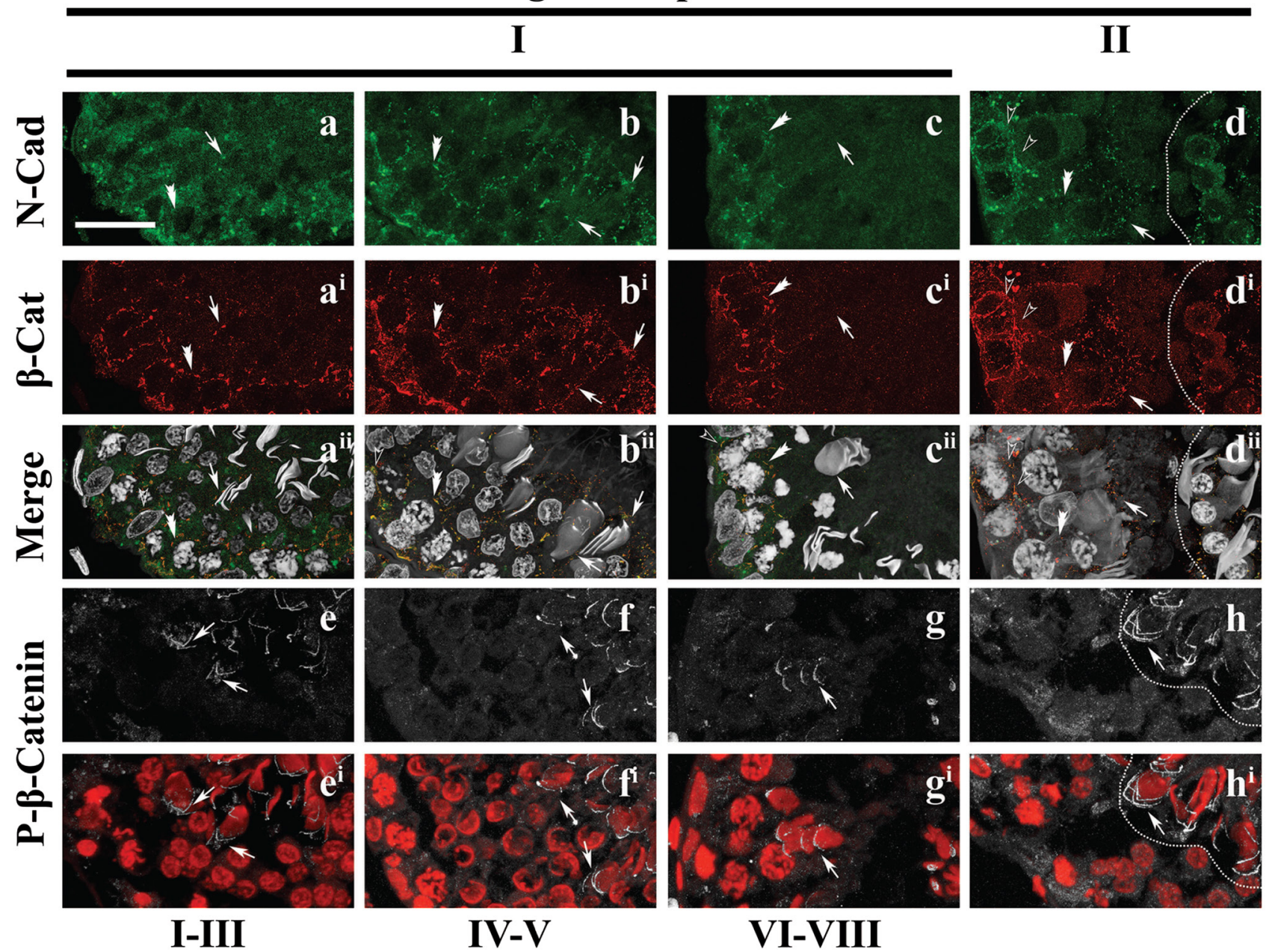

Figure 7 Confocal images of anti-N-cadherin (green), anti-B-catenin (red) and anti-P-B-catenin (white) immunofluorescence staining during

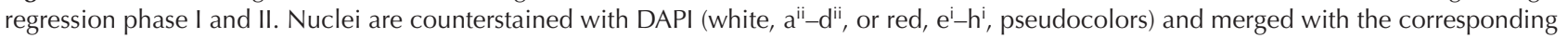
immunofluorescence images. At both regression phase I and II, N-cadherin and B-catenin signals always co-localise. At regression phase I with positive signals at spermatocytes $\left(\mathrm{a}-\mathrm{C}^{\mathrm{i}}\right.$, double arrowheads), at elongating spermatids from stage I to stage $\mathrm{V}\left(\mathrm{a}-\mathrm{b}^{\mathrm{i}}\right.$, arrows) and at round spermatids at stages IV-V (b-b', arrowheads). At regression phase II, N-cadherin and B-catenin co-localise at leptotene and pachytene spermatocytes $\left(\mathrm{d}-\mathrm{d}^{\mathrm{ii}}\right.$, empty arrows and double arrowheads, respectively) and at elongated spermatocytes ( $\mathrm{d}-\mathrm{d}^{\mathrm{ii}}$, arrows). Desquamated round spermatocytes (right to the dashed line) are also positive. Elongating spermatid heads are positive to the P-B-catenin immunosignals at both regression phase I and II (e- $\mathrm{h}^{\mathrm{i}}$, arrows). At the latter regression stage, the positive spermatids are present in the tubule lumen (right to the dashed line). The stages of the seminiferous epithelium cycle are annotated with Roman numeral. Bar, $20 \mu \mathrm{m}$.

in Sertoli cells/immature spermatids disengagement. Specifically, while in active testes, proteins of the A6B1-integrin/laminin 333 and N-cadherin/B-catenin adhesion complexes localise in the seminiferous epithelium with a spermatogenetic cycle-dependent pattern, this specific pattern is lost in regressing testes. In the latter, the relocation of B1-integrin, laminin G3, FAK, P-FAK, SRC, P-SRC, N-cadherin, B-catenin and P-B-catenin proteins, as conceptualised in Fig. 10, may reflect the dissociation of the A6B1-integrin/laminin 333 and $\mathrm{N}$-cadherin/B-catenin interlocks, thus contributing to immature post-meiotic germ cell release from Sertoli cells. Dissociation of these interlocks might be mediated by changes of protein levels and of the phosphorylation state of FAK, SRC and B-catenin (see below).

In the active testis, the localisation of the protein components of A6B1-integrin/laminin 333 and $\mathrm{N}$-cadherin/B-catenin adhesion complexes throughout the eight stages of the seminiferous epithelium cycle allowed to highlight the formation of these interlocks in relation to the progression of differentiating germ cell across the epithelium. A6B1-integrin/laminin 333 and $\mathrm{N}$-cadherin/ $\mathrm{N}$-cadherin interlocks formation was marked by the presence of small laminin G3, B1-integrin and of $\mathrm{N}$-cadherin signals associated with round spermatids at stage III of the cycle of the seminiferous epithelium. 


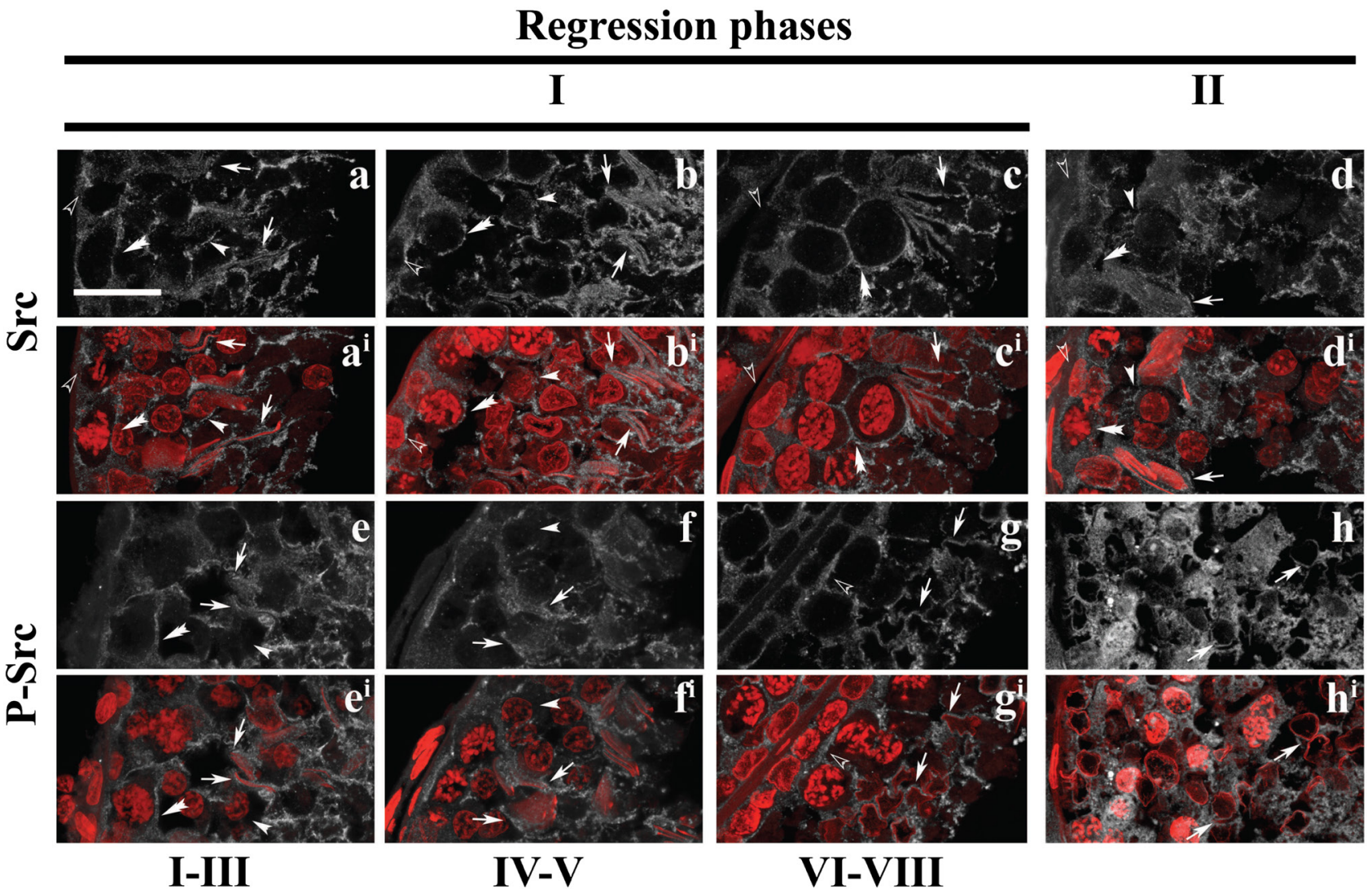

Figure 8 Confocal images of anti-SRC (a-d) and of anti-P-SRC (e-h) immunofluorescence staining of testis sections during regression phase I and

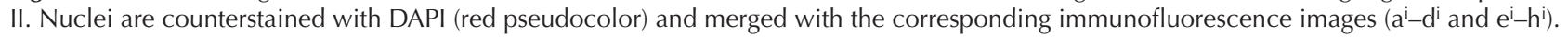
Both SRC and P-SRC contour spermatogonia (empty arrowheads), spermatocytes (double arrowheads), round (arrowheads) and elongating (arrow) spermatids. At regression phase II, P-SRC $\left(\mathrm{h}-\mathrm{h}^{\mathrm{i}}\right.$ ) is very bright. The stages of the seminiferous epithelium cycle are annotated with Roman numeral. Bar, $20 \mu \mathrm{m}$.

Then, the signals progressively decorate the spermatid heads until mature sperm are released into the tubule lumen at stage VI. This stage-specificity of the signals might reflect the timing of these adhesion complexes formation and dismantlement.

Interestingly, in the large hairy armadillo, apical ES formation seems to precede spermiation, differently from the rat, where the two events occur simultaneously. Apical ES may either replace desmosomes and gap junctions earlier than in rodents or coexist until they become the only anchoring structure conferring adhesion and polarity to spermatids (Mruk \& Cheng 2004, Wong et al. 2008, Vogl et al. 2008, Cheng \& Mruk 2010).

Similarly to B1-integrin, laminin G3 and N-cadherin the two non-receptor protein tyrosine kinases FAK and its binding partner SRC show specific localisation. While FAK is present near the basement membrane at the BTB, its phosphorylated form at Tyr ${ }^{397}$ is detectable at elongating spermatids at stages that just precede spermiation suggesting that, also in the armadillo, FAK phosphorylation is associated with the disassembly of the integrin/laminin G3 interlocks at the apical ES (Lie et al. 2012). This latter event appears to be mediated also by the presence of its binding partner, SRC, suggesting SRCmediated phosphorylation in the process of spermatid release (Wang et al. 2000, Lee \& Cheng 2005, Xiao et al. 2014). To this regard, the presence of P-SRC-Tyr ${ }^{416}$ has been detected at mature spermatids, lining up at the lumen of the tubule, only at stages IV and V. It has been suggested that c-SRC is a mediator of the disassembly of the apical ES and of the short-lived apical tubulobulbar complex, facilitating spermatid release (for a review see Chojnacka \& Mruk 2015).

B-catenin, a peripheral adaptor protein of the cadherin-cadherin interlocks, co-localises with $\mathrm{N}$-cadherin at spermatogonia, spermatocytes, round and elongating spermatids, marking their presence at the junction sites between Sertoli and germ cells. Instead, P-B-catenin-Tyr ${ }^{654}$ brightens at the head of elongating spermatids suggesting that the balance between the phosphorylated and non-phosphorylated form might be involved in the maintenance of both their polarisation (Chang et al. 2011) and back-and-forth changes of localisation (for a review Xiao et al. 2014). It is worth reminding that phosphorylation of B-catenin decreases its affinity for E-cadherin reducing cell 
A)
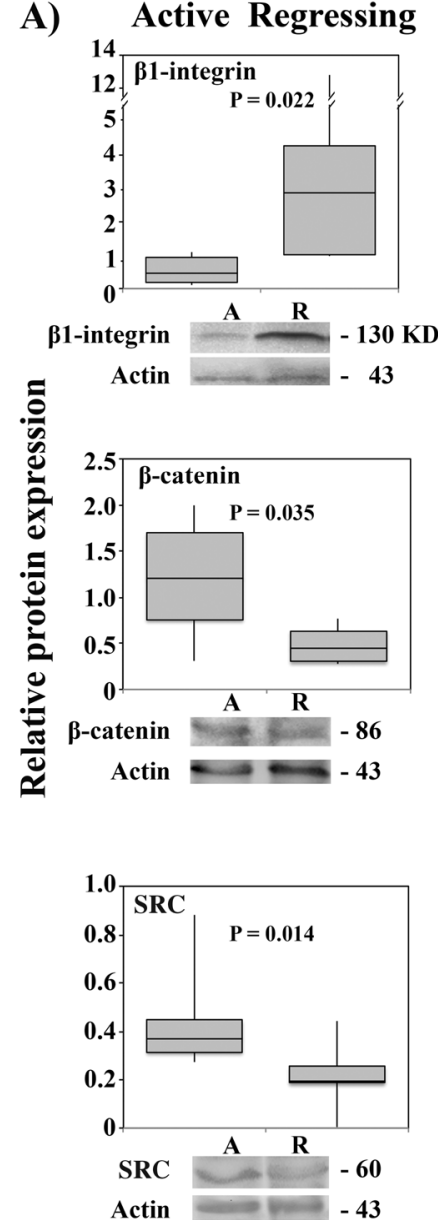

Active Regressing

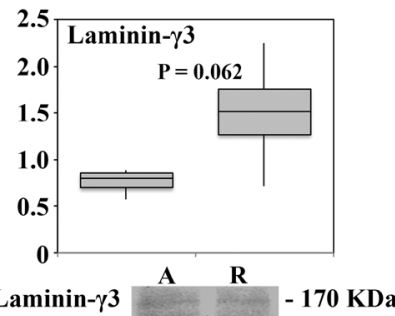

Actin
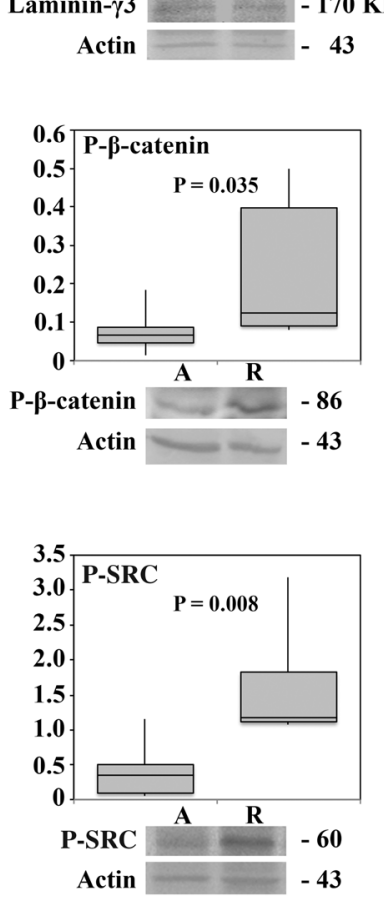

Active Regressing

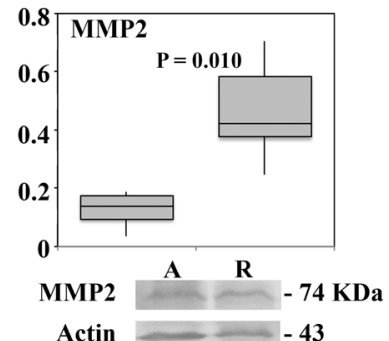

Actin

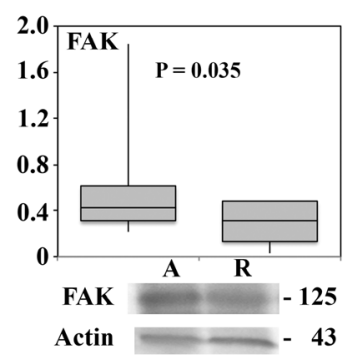

B)

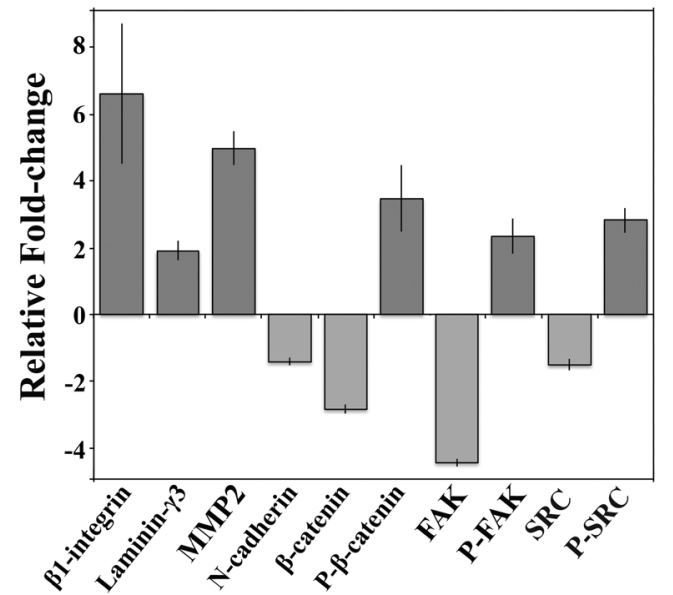

Figure 9 (A) Box plot of relative protein expression in active (A) or regressing (R) testes. Each box comprises $50 \%$ of the data (including second and third quartiles) and is bisected by the median value. The error bar indicates the min and max values recorded. The non-parametric Mann-Whitney test (see 'Results' section for details) revealed, for each protein, statistically significant differences when comparing the expression levels between $\mathrm{A}$ and $\mathrm{R}$ testes. For each target protein, representative immunoblotting images are reported for both $\mathrm{A}$ and $\mathrm{R}$ testes. Actin was used as quantitative reference marker. (B) Fold-change expression of mean quantitative protein values in the comparison between $\mathrm{A}$ and $R$ testes. Protein quantitation is based on five blots, from five different animals, for each protein analysed, with the exception of laminin G3 that was quantified on three blots from three different animals.

adhesion (Miravet et al. 2003, Lilien \& Balsamo 2005), thus contributing to the maintenance of a dynamic state of attachment/release of these junctions at the apical ES.

With the beginning of the non-reproductive season, occurring in autumn (May-June), when males display consistent drop of gonadal testosterone levels (Luaces et al. 2014), the quantitative pattern of expression of these adhesion proteins and their localisation changes significantly. The absence of B1-integrin/laminin G3 signals at round spermatids suggests possible failure in the formation of these interlocks, at the time when, in the active testis, they are built (stage III). This lack of signal at round spermatids and the thin fluorescence at elongating spermatids is paralleled by a major relocation of B1-integrin, SRC and P-SRC proteins within the Sertoli cell cytoplasm and of P-FAK at spermatids at the beginning of their elongation (stages VI-VIII). The observed relocation may reflect A6B1integrins uncoupling from their FAK/C-SRC cytoplasmic partner complex mediated by the increased levels of the phosphorylated forms of the two kinases. Similarly, the different localisation profile and the increased quantity of P-B-catenin-Tyr ${ }^{654}$ indicate that also the cadherin-catenin complex might be dissociated, likely contributing to the disassembly of the cadherin/catenin complex at the apical ES. This scenario is supported 


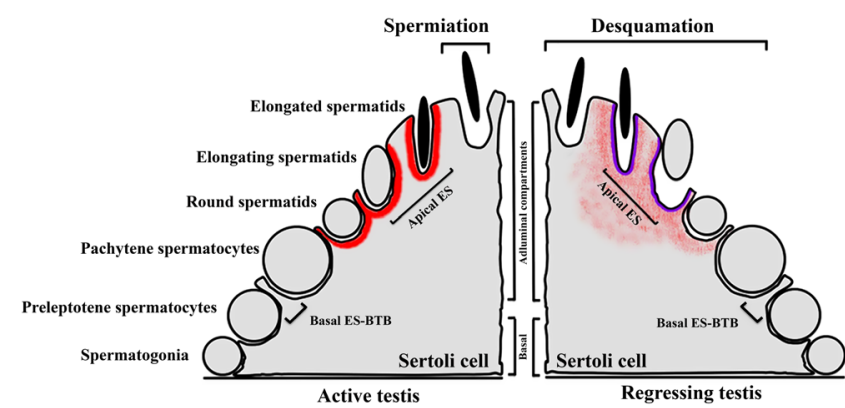

Figure 10 Schematic drawing of the histology of the seminiferous epithelium showing germ cells at different stages of their differentiation. In active testes the proteins of the A6B1 integrin/ laminin G3 and N-Cadherin/N-Cadherin interlocks, which are part of the apical ectoplasmic specialisation are localised (red mark) at elongating and elongated spermatids. In regressing testes their quantity, localisation (red mark) and phosphorylation profile (purple mark) changes in correlation to cell desquamation.

by previous findings using testosterone-suppressed testes showing that the Scr-mediated phosphorylation of the catenin/cadherin complex at both B-catenin and $\mathrm{N}$-cadherin determines the disruption of their binding (Lilien \& Balsamo 2005) and that of B-catenin, A-catenin and C-SRC thus contributing to the disassembly of the apical ES (Zhang et al. 2005, Lui \& Lee 2009). However, functional experiments are needed to identify those biomolecule(s) involved in the regulation of FAK, p-FAK, SRC and p-SRC signalling proteins and their role in determining the release of immature spermatids from Sertoli cells in regressing testes.

In summary, the use of a number of key proteins of the A6B1-integrin/laminin 333 and $\mathrm{N}$-cadherin/B-catenin interlocks contributed to fill in a gap of knowledge on the Sertoli/germ cell adhesion complexes during the cycle of the seminiferous epithelium in active testes and at the time of regression, as it occurs in nature during the circannual cycle. The extension of the taxonomic sampling to a Xenarthra species, one of the earliest offshoots among placentals (Asher et al. 2009), advances the present knowledge on how cell desquamation is executed at the beginning of the seminiferous epithelium regression in seasonal breeders.

\section{Declaration of interest}

The authors declare that there is no conflict of interest that could be perceived as prejudicing the impartiality of the research reported.

\section{Funding}

This work was supported by University of Pavia (FRG to S G and V M), Italian Ministry of Education, University and Research (Dipartimenti di Eccellenza Programme 2018-2022 to S G, M Z, V M, P R) and Kinesis Ltd (to M Z and S G) for the consumables necessary to carry out this study. M S M acknowledges support from Consejo Nacional de Investigaciones Científicas y Técnicas (PIP 0168), Argentina. J P L and L F R stages at the Laboratorio di Biologia dello Sviluppo were supported by the travelling scholarships programme of the Centro Internazionale Cooperazione per lo Sviluppo of the University of Pavia.

\section{Acknowledgments}

The authors thank Dr Antonio Manzo (University of Pavia, Italy) for the use of the ChemiDoc XRS system (Bio-Rad).

\section{References}

Asher RJ, Bennett N \& Lehmann T 2009 The new framework for understanding placental mammal evolution. Bioessays 31 853-864. (https://doi.org/10.1002/bies.200900053)

Bradford MM 1976 A rapid and sensitive method for the quantitation of microgram quantities of protein utilizing the principle of proteindye binding. Analytical Biochemistry 72 248-254. (https://doi. org/10.1016/0003-2697(76)90527-3)

Bex FJ \& Bartke A 1977 Testicular LH binding in the hamster: modification by photoperiod and prolactin 1. Endocrinology 100 1223-1226. (https:// doi.org/10.1210/endo-100-4-1223)

Beardsley A \& O'Donnell L 2003 Characterization of normal spermiation and spermiation failure induced by hormone suppression in adult rats. Biology of Reproduction 68 1299-1307. (https://doi.org/10.1095/ biolreprod.102.009811)

Beardsley A, Robertson DM \& O'Donnell L 2006 A complex containing $\alpha 6 \beta 1$-integrin and phosphorylated focal adhesion kinase between Sertoli cells and elongated spermatids during spermatid release from the seminiferous epithelium. Journal of Endocrinology 190 759-770. (https://doi.org/10.1677/joe.1.06867)

Berruti G \& Paiardi C 2014 The dynamic of the apical ectoplasmic specialization between spermatids and Sertoli cells: the case of the small GTPase Rap1. BioMed Research International 2014 635979. (https://doi. org/10.1155/2014/635979)

Cetica PD, Solari AJ, Merani MS, De Rosas JC \& Burgos MH 1998 Evolutionary sperm morphology and morphometry in armadillos. Journal of Submicroscopic Cytology and Pathology 30 309-314.

Chang YF, Lee-Chang JS, Harris KY, Sinha-Hikim AP \& Rao MK 2011 Role of $\beta$-catenin in post-meiotic male germ cell differentiation. PLOS ONE $\mathbf{6}$ e28039. (https://doi.org/10.1371/journal.pone.0028039)

Cheng CY \& Mruk DD 2010 A local autocrine axis in the testes that regulates spermatogenesis. Nature Reviews Endocrinology 6 380-395. (https://doi.org/10.1038/nrendo.2010.71)

Chojnacka K \& Mruk DD 2015 The Src non-receptor tyrosine kinase paradigm: new insights into mammalian Sertoli cell biology. Molecular Cell Endocrinology 415 133-142. (https://doi.org/10.1016/j.mce.2015.08.012)

Dadhich RK, Real FM, Zurita F, Barrionuevo FJ, Burgos M \& Jiménez R 2010 Role of apoptosis and cell proliferation in the testicular dynamics of seasonal breeding mammals: a study in the Iberian mole, Talpa occidentalis. Biology of Reproduction 83 83-91. (https://doi. org/10.1095/biolreprod.109.080135)

Dadhich RK, Barrionuevo FJ, Real FM, Lupiañez DG, Ortega E, Burgos M \& Jiménez R 2013 Identification of live germ-cell desquamation as a major mechanism of seasonal testis regression in mammals: a study in the Iberian mole (Talpa occidentalis). Biology of Reproduction 88 1-12. (https://doi.org/10.1095/biolreprod.112.106708)

Gliki G, Ebnet K, Aurrand-Lions M, Imhof BA \& Adams RH 2004 Spermatid differentiation requires the assembly of a cell polarity complex downstream of junctional adhesion molecule-C. Nature 431 320-324. (https://doi.org/10.1038/nature02877)

Jimenez R, Burgos M \& Barrionuevo FJ 2015 Circannual testis changes in seasonally breeding mammals. Sexual Development 9 205-215. (https:// doi.org/10.1159/000439039)

Leblond CP \& Clermont Y 1952 Definition of the stages of the cycle of the seminiferous epithelium in the rat. Annals of the New York Academy of Sciences 55 548-573. (https://doi.org/10.1111/j.1749-6632.1952.tb26576.x) 
Lee NP \& Cheng CY 2005 Protein kinases and adherens junction dynamics in the seminiferous epithelium of the rat testis. Journal of Cell Physiology 202 344-360. (https://doi.org/10.1002/jcp.20119)

Lee NP, Mruk D, Lee WM \& Cheng CY 2003 Is the cadherin/catenin complex a functional unit of cell-cell actin-based adherens junctions in the rat testis?. Biology of Reproduction 68 489-508. (https://doi. org/10.1095/biolreprod.102.005793)

Lie PP, Cheng CY \& Mruk DD 2010 Crosstalk between desmoglein-2/ desmocollin-2/Src kinase and coxsackie and adenovirus receptor/ZO-1 protein complexes, regulates blood-testis barrier dynamics. International Journal of Biochemistry Cell B 42 975-986. (https://doi.org/10.1016/j. biocel.2010.02.010)

Lie PP, Mruk DD, Mok KW, Su L, Lee WM \& Cheng CY 2012 Focal adhesion kinase-Tyr407 and-Tyr397 exhibit antagonistic effects on blood-testis barrier dynamics in the rat. PNAS 9 12562-12567. (https:// doi.org/10.1073/pnas.1202316109)

Lilien J \& Balsamo J 2005 The regulation of cadherin-mediated adhesion by tyrosine phosphorylation/dephosphorylation of $\beta$-catenin. Current Opinion in Cell Biology 17 459-465. (https://doi.org/10.1016/j. ceb.2005.08.009)

Luaces JP, Rossi LF, Merico V, Zuccotti M, Redi CA, Solari AJ, Merani MS \& Garagna S 2013 Spermatogenesis is seasonal in the large hairy armadillo, Chaetophractus villosus (Dasypodidae, Xenarthra, Mammalia). Reproduction, Fertility and Development 25 547-557. (https://doi. org/10.1071/RD12127)

Luaces JP, Rossi LF, Sciurano RB, Rebuzzini P, Merico V, Zuccotti M, Merani MS \& Garagna S 2014 Loss of Sertoli germ cell adhesion determines the rapid germ cell elimination during the seasonal regression of the seminiferous epithelium of the large hairy armadillo Chaetophractus villosus. Biology of Reproduction 90 48. (https://doi. org/10.1095/biolreprod.113.113118)

Lui WY \& Lee WM 2009 Molecular mechanisms by which hormones and cytokines regulate cell junction dynamics in the testis. Journal of Molecular Endocrinology 43 43-51. (https://doi.org/10.1677/JME-080174)

McCabe MJ, Tarulli GA, Meachem SJ, Robertson DM, Smooker PM \& Stanton PG 2010 Gonadotropins regulate rat testicular tight junctions in vivo. Endocrinology 151 2911-2922. (https://doi.org/10.1210/en.20091278)

Miravet S, Piedra J, Castaño J, Raurell I, Francí C, Duñach M \& de Herreros AG 2003 Tyrosine phosphorylation of plakoglobin causes contrary effects on its association with desmosomes and adherens junction components and modulates $\beta$-catenin-mediated transcription. Molecular and Cellular Biology 23 7391-7402. (https://doi.org/10.1128/ MCB.23.20.7391-7402.2003)

Mruk DD \& Cheng CY 2004 Cell-cell interactions at the ectoplasmic specialization in the testis. Trends in Endocrinology and Metabolism 15 439-447. (https://doi.org/10.1016/j.tem.2004.09.009)

O'Donnell L, Stanton PG, Bartles JR \& Robertson DM 2000 Sertoli cell ectoplasmic specializations in the seminiferous epithelium of the testosterone-suppressed adult rat. Biology of Reproduction 63 99-108. (https://doi.org/10.1095/biolreprod63.1.99)

Ozaki-Kuroda K, Nakanishi H, Ohta H, Tanaka H, Kurihara H, Mueller S, Irie K, Ikeda W, Sakai T, Wimmer E et al. 2002 Nectin couples cellcell adhesion and the actin scaffold at heterotypic testicular junctions. Current Biology 12 1145-1150. (https://doi.org/10.1016/S09609822(02)00922-3)

Russell LD \& Malone JP 1980 A study of Sertoli-spermatid tubulobulbar complexes in selected mammals. Tissue and Cell 12 263-285. (https:// doi.org/10.1016/0040-8166(80)90005-1)

Salanova M, Stefanini M, De Curtis I \& Palombi F 1995 Integrin receptor alpha 6 beta 1 is localized at specific sites of cell-to-cell contact in rat seminiferous epithelium. Biology of Reproduction 52 79-87. (https://doi. org/10.1095/biolreprod52.1.79)

Schneider CA, Rasband WS \& Eliceiri KW 2012 NIH image to Image J: 25 years of image analysis. Nature Methods 9 671-675. (https://doi. org/10.1038/nmeth.2089)

Shi SR, Chaiwun B, Young L, Cote RJ \& Taylor CR 1993 Antigen retrieval technique utilizing citrate buffer or urea solution for immunohistochemical demonstration of androgen receptor in formalin- fixed paraffin sections. Journal of Histochemistry and Cytochemical 41 1599-1604. (https://doi.org/10.1177/41.11.7691930)

Siu MK \& Cheng CY 2004 Interactions of proteases, protease inhibitors, and the $\beta 1$ integrin/laminin $\gamma 3$ protein complex in the regulation of ectoplasmic specialization dynamics in the rat testis 1. Biology of reproduction $\mathbf{7 0}$ 945-964. (https://doi.org/10.1095/biolreprod.103.023606)

Siu MK, Mruk DD, Lee WM \& Cheng CY 2003 Adhering junction dynamics in the testis are regulated by an interplay of $\beta 1$-integrin and focal adhesion complex-associated proteins. Endocrinology 144 2141-2163. (https://doi.org/10.1210/en.2002-221035)

Siu ER, Wong EW, Mruk DD, Porto CS \& Cheng CY 2009 Focal adhesion kinase is a blood-testis barrier regulator. PNAS 106 9298-9303. (https:// doi.org/10.1073/pnas.0813113106)

Siu MK, Wong CH, Xia W, Mruk DD, Lee WM \& Cheng CY 2011 The $\beta 1$-integrin-p-FA p130Cas-DOCK180-RhoA-vinculin is a novel regulatory protein complex at the apical ectoplasmic specialization in adult rat testes. Spermatogenesis 1 73-86. (https://doi.org/10.4161/spmg.1.1.15452)

Tarulli G, Meachem S, Schlatt S \& Stanton P 2008 Regulation of testicular tight junctions by gonadotrophins in the adult Djungarian hamster in vivo. Reproduction 135 867-877. (https://doi.org/10.1530/REP-07-0572)

Tsubota T, Howell-Skalla L, Nitta H, Osawa Y, Mason JI, Meiers PG, Nelson RA \& Bahr JM 1997 Seasonal changes in spermatogenesis and testicular steroidogenesis in the male black bear Ursus americanus. Journal of Reproduction Fertility 109 21-27. (https://doi.org/10.1530/ jrf.0.1090021)

Vogl AW, Vaid KS \& Guttman JA 2008 The Sertoli cell cytoskeleton. Advances in Experimental Medicine and Biology 636 186-211. (https:// doi.org/10.1007/978-0-387-09597-4_11)

Wang W, Wine RN \& Chapin RE 2000 Rat testicular Src: normal distribution and involvement in ethylene glycol monomethyl ether-induced apoptosis. Toxicology and Applied Pharmacology 163 125-134. (https:// doi.org/10.1006/taap.1999.8870)

Wan HT, Mruk DD, Tang EI, Xiao X, Cheng YH, Wong EW \& Cheng CY 2014 Role of non-receptor protein tyrosine kinases in spermatid transport during spermatogenesis. Seminars in Cell and Developmental Biology 30 65-74. (https://doi.org/10.1016/j.semcdb.2014.04.013)

Wong EW, Mruk DD \& Cheng CY 2008 Biology and regulation of ectoplasmic specialization, an atypical adherens junction type, in the testis. BBA-Biomembranes $\mathbf{1 7 7 8}$ 692-708. (https://doi.org/10.1016/j. bbamem.2007.11.006)

Xia W, Wong C, Lee N, Lee W \& Cheng C 2005 Disruption of Sertoli-germ cell adhesion function in the seminiferous epithelium of the rat testis can be limited to adherens junctions without affecting the blood-testis barrier integrity: an in vivo study using an androgen suppression model. Journal of Cellular Physiology 205 141-157. (https://doi.org/10.1002/jcp.20377)

Xiao X, Mruk DD, Wong CK \& Cheng CY 2014 Germ cell transport across the seminiferous epithelium during spermatogenesis. Physiology 29 286-298. (https://doi.org/10.1152/physiol.00001.2014)

Yan HH \& Cheng CY 2006 Laminin $\alpha 3$ forms a complex with $\beta 3$ and $\gamma 3$ chains that serves as the ligand for $\alpha 6 \beta 1$-integrin at the apical ectoplasmic specialization in adult rat testes. Journal of Biological Chemistry 281 17286-17303. (https://doi.org/10.1074/jbc.M513218200)

Young KA, Zirkin BR \& Nelson RJ 1999 Short photoperiods evoke testicular apoptosis in white-footed mice (Peromyscus leucopus). Endocrinology 140 3133-3139. (https://doi.org/10.1210/endo.140.7.6870)

Zhang J, Wong CH, Xia W, Mruk DD, Lee NP, Lee WM \& Cheng CY 2005 Regulation of Sertoli-germ cell adherens junction dynamics via changes in protein-protein interactions of the $\mathrm{N}$-cadherin- $\beta$-catenin protein complex which are possibly mediated by $\mathrm{c}$-Src and myotubularinrelated protein 2: an in vivo study using an androgen suppression model. Endocrinology 146 1268-1284. (https://doi.org/10.1210/en.2004-1194)

Received 4 January 2018

First decision 21 February 2018

Revised manuscript received 10 October 2018

Accepted 25 October 2018 